\title{
Mitotic kinase PBK/TOPK as a therapeutic target for adult T-cell leukemia/lymphoma
}

\author{
CHIE ISHIKAWA $^{1,2}$, MASACHIKA SENBA ${ }^{3}$ and NAOKI MORI ${ }^{1}$ \\ ${ }^{1}$ Department of Microbiology and Oncology, Graduate School of Medicine, \\ University of the Ryukyus, Nishihara, Okinawa 903-0215; ${ }^{2}$ Division of Health Sciences, \\ Transdisciplinary Research Organization for Subtropics and Island Studies, \\ University of the Ryukyus, Nishihara, Okinawa 903-0213; ${ }^{3}$ Department of Pathology, \\ Institute of Tropical Medicine, Nagasaki University, Nagasaki 852-8523, Japan \\ Received October 16, 2017; Accepted May 3, 2018
}

DOI: $10.3892 / \mathrm{ijo} .2018 .4427$

\begin{abstract}
Adult T-cell leukemia/lymphoma (ATLL) is a disorder involving human T-cell leukemia virus type 1 (HTLV-1)-infected T-cells characterized by increased clonal neoplastic proliferation. PDZ-binding kinase (PBK) [also known as T-lymphokine-activated killer cell-originated protein kinase (TOPK)] is a serine/threonine kinase expressed in proliferative cells and is phosphorylated during mitosis. In this study, the expression and phosphorylation of PBK/ TOPK were examined by western blot analysis and RT-PCR. We found that PBK/TOPK was upregulated and phosphorylated in HTLV-1-transformed T-cell lines and ATLL-derived T-cell lines. Notably, CDK1/cyclin B1, which phosphorylates PBK/TOPK, was overexpressed in these cells. HTLV-1 infection upregulated PBK/TOPK expression in peripheral blood mononuclear cells (PBMCs) in co-culture assays. The potent PBK/TOPK inhibitors, HI-TOPK-032, and fucoidan from brown algae, decreased the proliferation and viability of these cell lines in a dose-dependent manner. By contrast, the effect of HI-TOPK-032 on PBMCs was less pronounced. Treatment with HI-TOPK-032 resulted in $\mathrm{G}_{1}$ cell cycle arrest, and decreased CDK6 expression and pRb phosphorylation, which are critical determinants of progression through the $\mathrm{G}_{1}$ phase. In addition, HI-TOPK-032 induced apoptosis, as evidenced by morphological changes, the cleavage of poly(ADP-ribose) polymerase with the activation of caspase-3, -8 and -9 , and an increase in the sub- $\mathrm{G}_{1}$ cell population and APO2.7-positive cells. Moreover, HI-TOPK-032 inhibited
\end{abstract}

Correspondence to: Professor Naoki Mori, Department of Microbiology and Oncology, Graduate School of Medicine, University of the Ryukyus, 207 Uehara, Nishihara, Okinawa 903-0215, Japan E-mail: naokimori50@gmail.com

Key words: PDZ-binding kinase/T-lymphokine-activated killer celloriginated protein kinase, adult T-cell leukemia/lymphoma, human T-cell leukemia virus type 1 , nuclear factor- $\kappa \mathrm{B}$, activator protein-1, Akt, interferon-induced protein with tetratricopeptide repeats the expression of cellular inhibitor of apoptosis 2 (c-IAP2), $\mathrm{X}$-linked inhibitor of apoptosis protein (XIAP), survivin and myeloid cell leukemia-1 (Mcl-1), and induced the expression of Bak and interferon-induced protein with tetratricopeptide repeats (IFIT) 1, 2 and 3. It is noteworthy that the use of this inhibitor led to the inhibition of the phosphorylation of ІкB kinase (IKK) $\alpha, \operatorname{IKK} \beta$, I $\mathrm{B} \alpha \alpha$, phosphatase and tensin homolog (PTEN) and Akt, and to the decreased protein expression of JunB and JunD, suggesting that PBK/TOPK affects the nuclear factor- $\mathrm{KB}$, Akt and activator protein-1 signaling pathways. In vivo, the administration of HI-TOPK-032 suppressed tumor growth in an ATLL xenograft model. Thus, on the whole, this study on the identification and functional analysis of PBK/ TOPK suggests that this kinase is a promising molecular target for ATLL treatment.

\section{Introduction}

Adult T-cell leukemia/lymphoma (ATLL) is an aggressive neoplasm of $\mathrm{CD}^{+} \mathrm{T}$ cells linked to human T-cell leukemia virus type 1 (HTLV-1) infection (1). Although the molecular mechanisms responsible for the genesis of ATLL are not yet fully understood, there is a general agreement that HTLV-1 induces oncogenesis through the deregulation of selected cellular signaling pathways, such as nuclear factor- $\kappa \mathrm{B}$ (NF- $\mathrm{kB}$ ), activator protein-1 (AP-1) and Akt, resulting in the transactivation of the expression of numerous cellular genes, which leads to dysregulated growth and transformation (2-4). In particular, the viral regulatory protein Tax is thought to play important roles in the oncogenic process of ATLL (5).

Despite advances in the development of novel therapeutic agents, many ATLL patients are resistant to chemotherapy and exhibit a poor prognosis (1). Therefore, novel and innovative approaches are greatly needed in order to advance ATLL treatment options. As ATLL cells are adapted to the dysregulation of kinases, it is compelling to target them to lead to marked antitumor responses.

PDZ-binding kinase (PBK) [also known as T-lymphokineactivated killer cell-originated protein kinase (TOPK)] is a serine/threonine kinase known to be highly expressed in hematologic neoplasms, such as myeloid leukemia and 
B-cell lymphoma (6-8). By contrast, its expression is limited to the testis in normal organs and tissues (6). The expression of PBK/TOPK is upregulated and phosphorylated during mitosis (6-8). It binds to and is phosphorylated at Thr9 and is activated by the CDK1/cyclin B1 complex $(9,10)$. PBK/TOPK is included in the 'consensus stemness ranking signature' gene list, which is upregulated in cancer stem cell-rich tumors, and associated with a poor prognosis in various types of tumor (11). These studies suggest that PBK/TOPK may exhibit an oncogenic cellular function and its inhibition may be useful in cancer therapy.

In this study, we report the overexpression of PBK/TOPK in HTLV-1-infected T-cell lines, and that treatment with HI-TOPK-032 and fucoidan, PBK/TOPK inhibitors, results in the inhibition of the growth and viability of these cell lines. We demonstrate that HI-TOPK-032 induces $\mathrm{G}_{1}$ cell cycle arrest and apoptosis by affecting the NF- $\kappa$ B, Akt, AP-1 and interferon (IFN) signaling pathways. Furthermore, we demonstrated the administration of HI-TOPK-032 results in the suppression of tumor growth in a xenograft model. These results suggest that $\mathrm{PBK} / \mathrm{TOPK}$ may be a promising molecular target in ATLL treatment.

\section{Materials and methods}

Reagents and antibodies. HI-TOPK-032 (cat. no. 614849) was purchased from Calbiochem (San Diego, CA, USA), dissolved in dimethyl sulfoxide (cat. no. 13407-45, Nacalai Tesque, Inc., Kyoto, Japan). Fucoidan was prepared from the brown algae Cladosiphon okamuranus Tokida cultivated in Okinawa as previously described in detail (12). Antibodies against PBK/TOPK (cat. no. 4942), phospho-PBK/TOPK (Thr9) (cat. no. 4941), Bcl-xL (cat. no. 2762), Bax (cat. no. 2772), Bak (cat. no. 3814), survivin (cat. no. 2808), phosphatase and tensin homologue (PTEN) (cat. no. 9556), phospho-PTEN (Ser380) (cat. no. 9551), Akt (cat. no. 9272), phospho-Akt (Thr308) (cat. no. 13038), phospho-Akt (Ser473) (cat. no. 4060), phospho-IкB $\alpha$ (Ser32 and 36) (cat. no. 9246), ІкB kinase (IKK) $\alpha$ (cat. no. 2682), IKK $\beta$ (cat. no. 2684), phospho-IKK $\alpha / \beta$ (Ser176/180 and Ser177/181) (cat. no. 2694), cleaved caspase-3 (cat. no. 9664), cleaved caspase-8 (cat. no. 9496), cleaved caspase-9 (cat. no. 9501) and poly(ADP-ribose) polymerase (PARP) (cat. no. 9541) were purchased from Cell Signaling Technology, Inc. (Beverly, MA, USA). Antibodies against cyclin B1 (cat. no. MS-868), CDK1 (cat. no. MS-275), CDK6 (cat. no. MS-398), retinoblastoma protein (pRb) (cat. no. MS-107) and actin (cat. no. MS-1295) were obtained from Neomarkers, Inc. (Fremont, CA, USA). Antibodies against XIAP (cat. no. M044-3) and phospho-pRb (Ser780) (cat.no. M054-3S) were purchased from Medical \& Biological Laboratories, Co. (Aichi, Japan). Antibodies against c-IAP2 (cat.no. sc-7944), Mcl-1 (cat. no. sc-819), IкB $\alpha$ (cat. no. sc-371), JunB (cat. no. sc-46), JunD (cat. no. sc-74), IFN-induced protein with tetratricopeptide repeats (IFIT)1 (cat. no. sc-134948), IFIT2 (cat. no. sc-390724), IFIT3 (cat. no. sc-393396) and NF- $\kappa$ B subunits p50 (cat. no. sc-114X), p52 (cat. no. sc-298X), RelA (cat. no. sc-109X), c-Rel (cat. no. sc-70X) and RelB (cat. no. sc-226X) and AP-1 subunits c-Fos (cat. no. sc-52X), FosB (cat. no. sc-48X), Fra-1 (cat. no. sc-605X), Fra-2 (cat.no. sc-604X), c-Jun (cat.no. sc-45X), JunB (cat.no. sc-46X) and JunD (cat. no. sc-74X) for supershift assay were obtained from Santa Cruz Biotechnology, Inc. (Santa Cruz, CA, USA). Lt-4, an antibody against Tax, was previously described (13).

Cells and cell culture. The HTLV-1-transformed MT-2, MT-4, C5/MJ, SLB-1 and HUT-102, and ATLL-derived MT-1, TL-OmI and ED-40515(-) T-cell lines, were maintained in RPMI-1640 medium (cat. no. 30264-56; Nacalai Tesque, Inc.) supplemented with $10 \%$ heat-inactivated fetal bovine serum (Biological Industries, Kibbutz Beit Haemek, Israel) and $1 \%$ penicillin/streptomycin (cat. no. 09367-34, Nacalai Tesque, Inc.) at $37^{\circ} \mathrm{C}$ in a humidified incubator under $5 \% \mathrm{CO}_{2}$. The C5/MJ, HUT-102 and MT-1 cells were obtained from Fujisaki Cell Center, Hayashibara Laboratories, Inc. (Okayama, Japan). The MT-2 and MT-4 cells were kindly provided by Dr Naoki Yamamoto (Tokyo Medical and Dental University, Tokyo, Japan). The SLB-1 and ED-40515(-) cells were provided by Dr Diane Prager (UCLA School of Medicine, Los Angeles, CA, USA) and Dr Michiyuki Maeda (Kyoto University, Kyoto, Japan), respectively. The TL-OmI cell line was provided by Dr Masahiro Fujii (Niigata University, Niigata, Japan). The study also included peripheral blood mononuclear cells (PBMCs) obtained from healthy donors (cat. no. HC-0001; Lifeline Cell Technology, Frederick, MD, USA). The PBMCs were stimulated with $20 \mu \mathrm{g} / \mathrm{ml}$ of phytohemagglutinin (PHA) (cat. no. L8754; Sigma-Aldrich Co., St. Louis, MO, USA) for $72 \mathrm{~h}$.

HTLV-1 infection by co-cultivation. The MT-2 cells that produce viral particles were pre-treated with $200 \mu \mathrm{g} / \mathrm{ml}$ of mitomycin C (MMC) (cat. no. M0503; Sigma-Aldrich Co.) for $1 \mathrm{~h}$, pipetted vigorously, and washed 3 times with phosphatebuffered saline. PBMCs from healthy donors (Lifeline Cell Technology) and MMC-treated MT-2 cells were co-cultured in the presence of $10 \mathrm{ng} / \mathrm{ml}$ of interleukin (IL)-2 (kindly provided by Takeda Pharmaceutical Company Ltd., Osaka, Japan). The culture medium was half-changed with fresh medium supplemented with IL-2 every 3 days. As the MT- 2 cells were pre-treated extensively with MMC, no discernible MT-2 cells were found.

Western blot analysis. Whole cell extracts were prepared by subjecting the treated cells to lysis with lysis buffer [62.5 mM Tris-HCl (pH 6.8) (cat. no. 35434-21), 2\% sodium dodecyl sulfate (cat. no. 31607-65), 10\% glycerol (cat. no. 17045-65), 6\% 2-mercaptoethanol (cat. no. 21438-82; all from Nacalai Tesque, Inc.) and $0.01 \%$ bromophenol blue (cat. no. 021-02911; Wako Pure Chemical Industries, Osaka, Japan)]. Protein concentrations were determined using a commercial kit (DC Protein Assay, cat. no. 5000116JA; Bio-Rad Laboratories, Inc., Hercules, CA, USA). Lysate protein $(20 \mu \mathrm{g})$ was subjected to $8-15 \%$ sodium dodecyl sulfate-polyacrylamide gels (SDS-PAGE), electrotransferred onto polyvinylidene difluoride membranes (cat. no. IPVH00010EMD; Millipore, Darmstadt, Germany). The membranes were blocked with $4 \%$ non-fat dry milk (cat no. 9999; Cell Signaling Technology, Inc.) for $1 \mathrm{~h}$ at room temperature, and blotted overnight with the respective antibody $(1: 1,000)$. Finally, the blots were hybridized with horseradish peroxidase-conjugated secondary anti-mouse (1:1,000) (cat. no. 7076; Cell Signaling Technology, Inc.) 
Table I. Primer sequences used in RT-PCR.

\begin{tabular}{lll}
\hline Name & \multicolumn{1}{c}{ Forward (5') } & \multicolumn{1}{c}{ Reverse (3') } \\
\hline PBK/TOPK & AGACCCTAAAGATCGTCCTTCTG & GTGTTTTAAGTCAGCATGAGCAG \\
Tax & CCGGCGCTGCTCTCATCCCGGT & GGCCGAACATAGTCCCCCAGAG \\
HBZ & GAATTGGTGGACGGGCTATTATC & TAGCACTATGCTGTTTCGCCTTC \\
IL-2R $\alpha$ & ATCCCACACGCCACATTCAAAGC & TGCCCCACCACGAAATGATAAAT \\
IFIT1 & GACAGGAAGCTGAAGGAGAAAA & TAGCAAAGCCCTATCTGGTGAT \\
IFIT2 & ACAAGGCCATCCACCACTTTAT & CCCAGCAATTCAGGTGTTAACA \\
c-IAP2 & CCATATGCTCACTCAGATGATGT & GTGTATCATCTCCACAGAGAGTT \\
Survivin & GGCATGGGTGCCCCGACGTTG & CAGAGGCCTCAATCCATGGCA \\
Bak & TGAAAAATGGCTTCGGGGCAAGGC & TCATGATTTGAAGAATCTTCGTACC \\
GAPDH & GCCAAGGTCATCCATGACAACTTTGG & GCCTGCTTCACCACCTTCTTGATGTC
\end{tabular}

or anti-rabbit IgG antibody (1:1,000) (cat. no. 7074; Cell Signaling Technology, Inc.), and visualized using an enhanced chemiluminescence reagent (cat. no. RPN2232; Amersham Biosciences Corp., Piscataway, NJ, USA).

DNA microarray analysis. The HUT-102 and MT-2 cells were treated with $5 \mu \mathrm{M}$ of HI-TOPK-032. After $24 \mathrm{~h}$, total RNA was extracted using the RNeasy Plus Mini kit (Qiagen, Hilden, Germany). Microarray analysis using a SurePrint G3 Human GE 8x60 K Microarray kit version 3.0 (Agilent Technologies, Inc., Waldbronn, Germany) was performed as previously described (14).

$R T$-PCR. TRIzol reagent (cat. no. 15596026; Invitrogen Life Technologies, Carlsbad, CA, USA) was used to extract total RNA from the cells. A total of $1 \mu \mathrm{g}$ RNA was reverse transcribed into cDNA using a PrimeScript RT-PCR kit (cat. no. RR014A; Takara Bio, Inc., Otsu, Japan). The sequencespecific primers used for RT-PCR are summarized in Table I. The PCR cycling conditions were as follows: $94^{\circ} \mathrm{C}$ for $2 \mathrm{~min}$, followed by $25-35$ cycles of $94^{\circ} \mathrm{C}$ for $1 \mathrm{~min}, 54-60^{\circ} \mathrm{C}$ for $1 \mathrm{~min}$ and $72^{\circ} \mathrm{C}$ for $1 \mathrm{~min}$, with a final extension step of $72^{\circ} \mathrm{C}$ for 5 min.

Cell proliferation and cytotoxic assay. The water-soluble tetrazolium (WST)-8 uptake method was used to assess the cell proliferative and toxic effects of HI-TOPK-032 $(0.31-20 \mu \mathrm{M})$ and fucoidan $(0.13-6 \mathrm{mg} / \mathrm{ml})$ for $48 \mathrm{~h}$. The cells were plated in 96-well flat microtiter plates in triplicate and treated as indicated for $48 \mathrm{~h}$ prior to the WST-8 assay. A total of $10 \mu \mathrm{l}$ of the WST-8 reagent (cat. no. 07553-44; Nacalai Tesque, Inc.) were added to each well. After a 4-h reaction, WST-8 reduction was measured at $450 \mathrm{~nm}$ using a Wallac 1420 Multilabel Counter (PerkinElmer, Inc., Waltham, MA, USA). The values were normalized to the untreated control samples.

Analysis of cell apoptosis. The cells were treated with HI-TOPK-032 (0.63-20 $\mu \mathrm{M})$ for $24 \mathrm{~h}$ and then permeabilized by incubation on ice for $20 \mathrm{~min}$ with $100 \mu \mathrm{g} / \mathrm{ml}$ of digitonin, and treated with the phycoerythrin-conjugated APO2.7 antibody (cat. no. IM2088; Beckman Coulter, Inc., Marseille, France) for $15 \mathrm{~min}$ at room temperature. After staining with
APO2.7 antibody, the induction of apoptosis was determined by Epics XL flow cytometry (Beckman Coulter, Inc., Brea, CA, USA). In addition, for the analysis of morphological changes in the nuclei, the cells were stained by $10 \mu \mathrm{g} / \mathrm{ml}$ of Hoechst 33342 (cat. no. 346-07951; Dojindo Molecular Technologies, Inc., Kumamoto, Japan) and observed under a Leica DMI6000 microscope (Leica Microsystems, Wetzlar, Germany).

Measurement of caspase activity. Caspase activity was assessed using Colorimetric Caspase Assay kits (cat. nos. 4800, 4805 and 4810; Medical \& Biological Laboratories, Co.). Briefly, the cell extracts were recovered using the cell lysis buffer supplied with the kit, and assessed for caspase-3, -8 and -9 activities using respective colorimetric probe. The kits are based on the detection of chromophore $\mathrm{Q}$-nitroanilide after cleavage from caspase-specific labeled substrates. Colorimetric readings were determined with a microplate reader (Wallac 1420 Multilabel Counter; PerkinElmer, Inc.).

Cell cycle analysis. The cells were stained with the CycleTEST Plus DNA Reagent kit (cat. no. 340242; Becton-Dickinson Immunocytometry Systems, San Jose, CA, USA). The cell cycle distribution was analyzed by an Epics XL flow cytometry that uses the MultiCycle software (version 3.0; Phoenix Flow Systems, San Diego, CA, USA). The population of nuclei at each phase of the cell cycle was determined, and apoptotic cells with hypodiploid DNA content were detected in the sub- $\mathrm{G}_{1}$ region.

Electrophoretic mobility shift assay (EMSA). To determine $\mathrm{NF}-\kappa \mathrm{B}$ and AP-1 activation, we prepared nuclear extracts from the HI-TOPK-032-treated cells and performed EMSA, as previously described in detail (15). Nuclear extracts were incubated with ${ }^{32} \mathrm{P}$-labeled probes. The top strand sequences of the oligonucleotide probes or competitors were as follows: For a typical NF- $\kappa \mathrm{B}$ element of the IL-2 receptor $\alpha$ chain $(I L-2 R \alpha)$ gene, 5'-GATCCGGCAGGGGAATCTCCCTCTC-3' and for the consensus AP-1 element of the $I L-8$ gene, 5'-GATCGTGATGACTCAGGTT-3'. The above underlined sequences are the NF- $\mathrm{B}$ and AP-1 binding sites, respectively. In the competition experiments, nuclear extracts were preincubated for $15 \mathrm{~min}$ with 100 -fold excess of unlabeled 
oligonucleotides. For supershift assays, nuclear extracts were incubated with antibodies against NF- $\mathrm{KB}$ or AP-1 subunits for $45 \mathrm{~min}$ at room temperature before the complex was analyzed by EMSA. The dried gels were visualized using a Pharos FX Plus System (Bio-Rad Laboratories Inc.).

Xenograft tumor model. Eighteen 5-week-old female C.B-17/Icr-severe combined immunodeficient (SCID) mice were obtained from Kyudo, Co. (Tosu, Japan). The HUT-102 cells ( $1 \times 10^{7} / 0.2 \mathrm{ml}$ RPMI-1640 medium) were inoculated subcutaneously into the post-auricular region of the SCID mice. The mice were divided into 2 groups $(n=9$, each). HI-TOPK-032 was solubilized in $5.2 \%$ polyethylene glycol 400 (cat. no. 161-09065; Wako Pure Chemical Industries) and 5.2\% Tween-80 (cat. no. 231181; BectonDickinson, Franklin Lakes, NJ, USA), and administrated at a dose of $12.5 \mathrm{mg} / \mathrm{kg}$ intraperitoneally 5 times a week. The treatment was continued for 4 weeks, beginning on the day after cell inoculation. The control group received the vehicle (5.2\% polyethylene glycol 400 and 5.2\% Tween-80) only. The tumor diameter was measured weekly with a shifting caliper and tumor volume was calculated. The body weights were also measured weekly. All mice were sacrificed on day 28 . The tumors were excised and their weights measured. Blood samples were collected from mice under deep terminal anesthesia by cardiac puncture, and the sera were stored at $-80^{\circ} \mathrm{C}$ until assayed for soluble IL-2R $\alpha$ [soluble cluster of differentiation 25 (sCD25)] and sCD30. This experiment was performed according to the Guidelines for Animal Experimentation of the University of the Ryukyus (Nishihara, Japan), and was approved by the Animal Care and Use Committee of the University (reference no. A2016073).

Morphological analysis of tumor tissues and terminal deoxynucleotidyl transferase deoxyuridine triphosphate nick end labeling (TUNEL) assay. The tumor specimens were collected from the treated or untreated mice, fixed in formalin solution (Wako Pure Chemical Industries), dehydrated through graded ethanol series (Japan Alcohol Selling Co., Tokyo, Japan), and embedded in paraffin (cat. no. 09620; Sakura Finetek Japan Co., Tokyo, Japan). The paraffin-embedded specimens of ATLL tumors were stained with hematoxylin and eosin (H\&E, cat. nos. 234-12 and 1159350025; Merck, Darmstadt, Germany), and examined histologically. The analysis of DNA fragmentation by TUNEL assay was performed using a commercial kit (cat. no. 11684817910; Roche Applied Science, Penzberg, Germany) according to the instructions supplied by the manufacturer. The cells were examined under a light microscope (Axioskop 2 Plus) with an Achroplan 40x/0.65 lens (both from Zeiss, Hallbergmoos, Germany). Images were acquired with an AxioCam 503 color and AxioVision LE64 software (Zeiss).

Biomarker analysis. Serum concentrations of human sCD25 (cat. no. 950.500.048; Diaclone SAS, Besançon, France) and human sCD30 (cat. no. BMS240; Affymetrix eBioscience, San Diego, CA, USA) were assessed in the treated and untreated mice by enzyme-linked immunosorbent assay (ELISA), according to the protocol supplied by the manufacturer.
Statistical analysis. The results are expressed as the means \pm standard deviation (SD). The Student's t-test or ANOVA with Tukey-Kramer statistical tests were used to evaluate the data of 2 groups or more than 2 groups, respectively. Differences were considered statistically significant at $\mathrm{P}<0.05$.

\section{Results}

Upregulation and phosphorylation of PBK/TOPK in HTLV-1infected T-cell lines. To assess PBK/TOPK expression in HTLV-1-infected T-cell lines, we examined the protein levels of PBK/TOPK. The protein levels were determined in 5 HTLV-1-transformed T-cell lines (Fig. 1A, lanes 1-5) and in 3 ATLL-derived T-cell lines (Fig. 1A, lanes 6-8) and compared with those in PBMCs from two healthy donors (Fig. 1A, lanes 9 and 10), using western blot analysis. HTLV-1-transformed T-cell lines constitutively expressed Tax at protein and mRNA levels (Fig. 1A and B). Western blot analysis revealed that PBK/ TOPK protein expression was markedly higher in the HTLV-1infected T-cell lines than in the PBMCs from healthy donors (Fig. 1A). RT-PCR analysis confirmed the elevated mRNA expression of PBK/TOPK in the HTLV-1-infected T-cell lines compared to PBMCs from healthy donors (Fig. 1B). The phosphorylation of PBK/TOPK by CDK1/cyclin B1 is required for its mitotic activity $(9,10)$. We found that PBK/TOPK was constitutively phosphorylated and CDK1/cyclin B1 was strongly expressed in all HTLV-1-infected T-cell lines. By contrast, no phosphorylation of PBK/TOPK and no expression of CDK1/cyclin B1 were detected by western blot analysis in the PBMCs of healthy donors (Fig. 1A, lanes 9 and 10). Notably, PHA stimulation induced the expression of PBK/TOPK at the protein and mRNA levels, the phosphorylation of PBK/TOPK, and the protein expression of CDK1/cyclin B1 in PBMCs (Fig. 1A and B).

PBK/TOPK expression in HTLV-1-infected cells. To examine whether HTLV-1 infection can induce PBK/TOPK expression, we co-cultured PBMCs and MMC-treated MT-2 cells. At 7 days after co-cultivation, the PBMCs were harvested for the assessment of viral gene expression by RT-PCR. The PBMCs co-cultured with MMC-treated MT-2 cells expressed Tax mRNA (Fig. 1C). Furthermore, the expression levels of PBK/TOPK and IL-2R $\alpha$, one of the known target genes of Tax (16), increased in these cells following induction of Tax expression. These results suggest that HTLV-1 infection induces the expression of PBK/TOPK in PBMCs.

HI-TOPK-032 inhibits cell viability. The PBK/TOPK inhibitor, HI-TOPK-032, is known to bind the active site of PBK/TOPK (17). In this study, HI-TOPK-032 suppressed the phosphorylation of PBK/TOPK (Fig. 2A). To examine the effects of HI-TOPK-032, HTLV-1-infected T-cell lines were treated with various concentrations of HI-TOPK- 032 for $48 \mathrm{~h}$, and cell viability was assessed by WST- 8 assay. Cell viability was inhibited in a dose-dependent manner (Fig. 2B). The effect of HI-TOPK-032 on the viability of PBMCs was less pronounced at the $5 \mu \mathrm{M}$ concentration (Fig. 2C).

HI-TOPK-032 induces apoptosis with the cleavage and activation of caspases. First, the morphological changes 
A

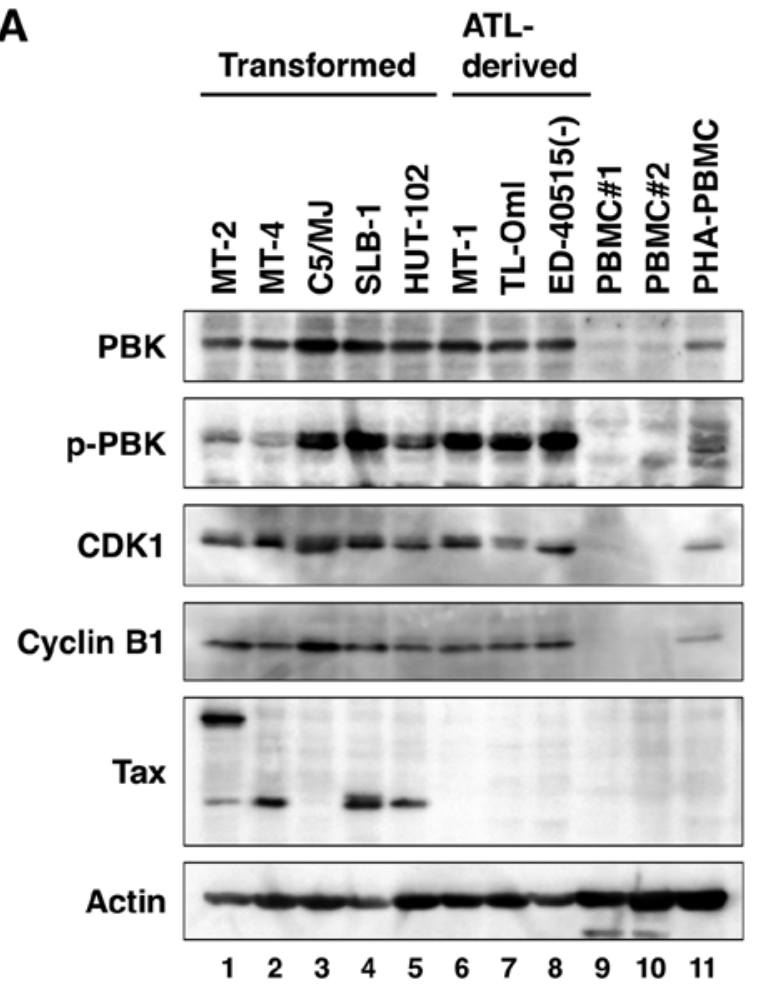

B

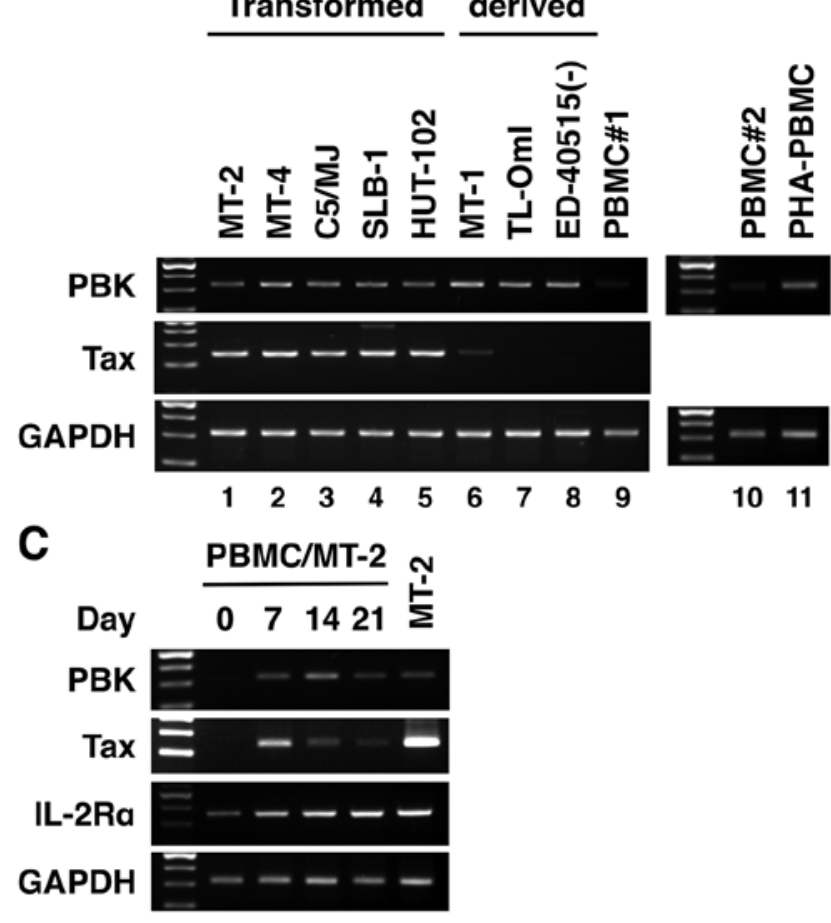

Figure 1. HTLV-1 infection induces PBK/TOPK expression. (A) Western blot analysis performed on 5 HTLV-1-transformed T-cell lines (lanes 1-5) and 3 ATLL-derived T-cell lines (lanes 6-8) revealed a clear upregulation of PBK/TOPK and CDK1/cyclin B1, and phosphorylation of PBK/TOPK, compared to normal PBMCs (lanes 9 and 10). PBMCs from a healthy volunteer were treated with PHA for $72 \mathrm{~h}$ (PHA-PBMC; lane 11). Actin was used as the control. (B) RT-PCR analysis of PBK/TOPK expression in HTLV-1-transformed T-cell lines (lanes 1-5), ATLL-derived T-cell lines (lanes 6-8), PBMCs from healthy volunteers (lanes 9 and 10) and PHA-PBMC (lane 11). Expression of GAPDH was used as the control. (C) Expression of PBK/TOPK in HTLV-1-infected PBMCs. PBMCs from a healthy volunteer were co-cultured with MMC-treated MT-2 cells. After co-cultivation, cells were harvested, and the expression of the indicated genes was analyzed by RT-PCR.

A

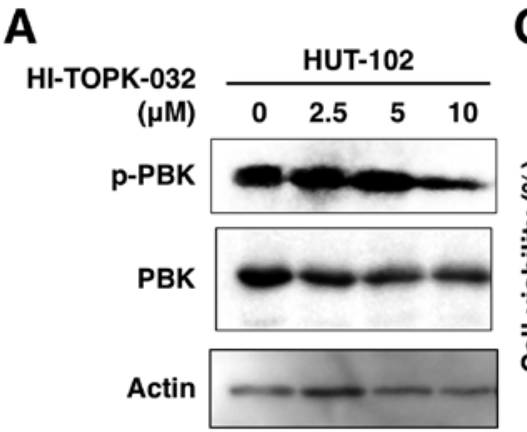

B

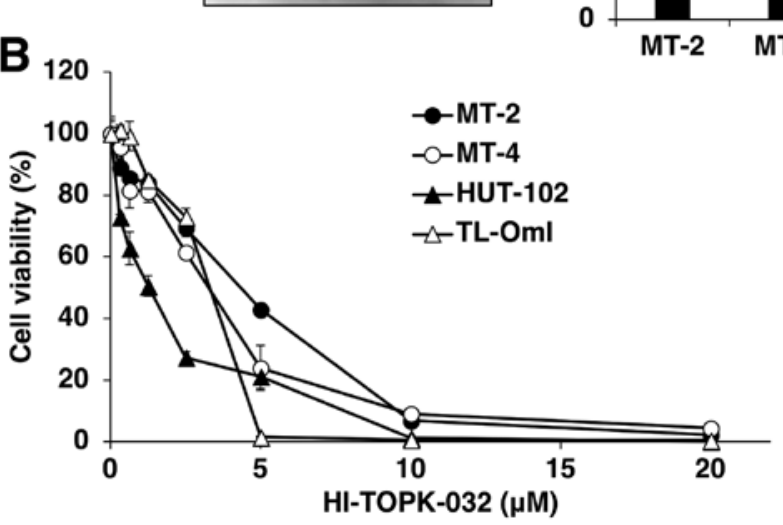

C

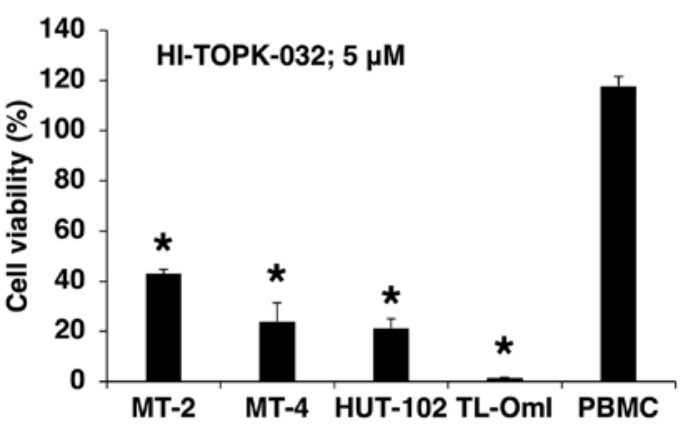

Figure 2. Effect of HI-TOPK-032 on HTLV-1-infected T-cell lines. (A) Effect of HI-TOPK-032 on PBK/TOPK phosphorylation. Cells were treated with HI-TOPK-032 for $24 \mathrm{~h}$ and analyzed by western blot analysis. (B) HI-TOPK-032 inhibited the viability of HTLV-1-infected T-cell lines. Four HTLV-1infected T-cell lines were treated with increasing concentrations of HI-TOPK-032. After $48 \mathrm{~h}$, cell viability was determined by WST-8 assay. (C) Effect of HI-TOPK-032 on the viability of PBMCs. HTLV-1-infected T-cell lines and PBMCs from healthy donors were treated with $5 \mu$ M HI-TOPK-032 for 48 h. Viable cells were plotted relative to medium control (100\%). Data are the means $\pm \mathrm{SD}$ of triplicate cultures. ${ }^{\mathrm{P}}<0.0005$ vs. PBMCs. 


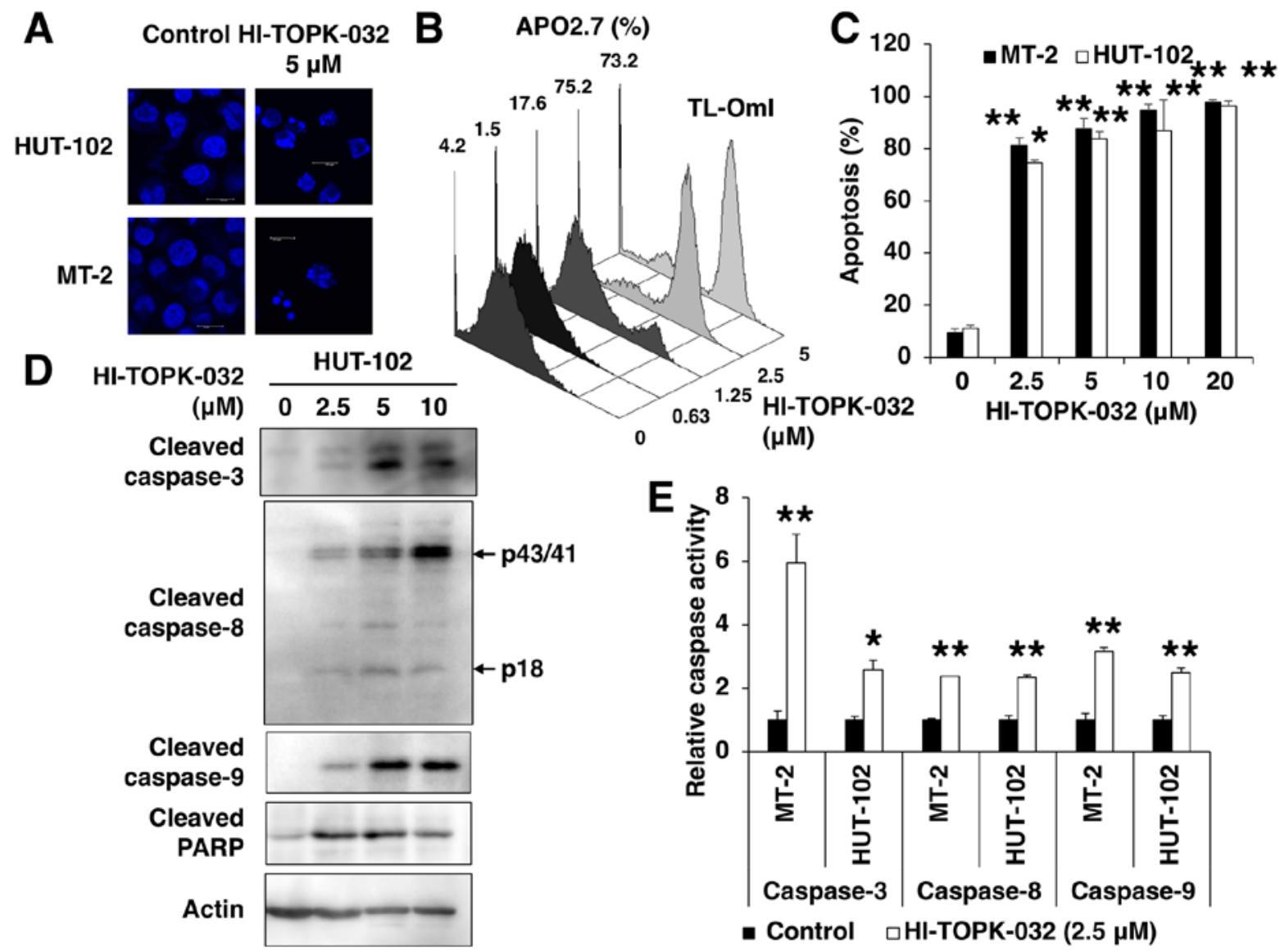

Figure 3. HI-TOK-032 induces the apoptosis of HTLV-1-infected T-cell lines. (A) Fluorescence micrograph of cells stained with Hoechst 33342 . Cells were treated with $5 \mu \mathrm{M}$ of HI-TOPK- 032 for $48 \mathrm{~h}$, and analyzed by microscopy after Hoechst 33342 staining. (B and C) Quantitative analysis of apoptosis by APO2.7 staining. Cells were treated with various concentrations of HI-TOPK-032 for $24 \mathrm{~h}$, and flow cytometry analysis was performed to detect APO2.7 expression levels. (B) Representative histograms. Numbers in the histograms indicate the frequency (\%) corresponding to mitochondrial APO2.7 expression in TL-OmI cells. (C) Percentage of APO2.7-positive cells. Data are the means $\pm \mathrm{SD}$ of triplicate cultures. ${ }^{*} \mathrm{P}<0.001$ and ${ }^{* *} \mathrm{P}<0.0005$, vs. vehicle-treated control (D) Expression levels of cleaved caspase-3, -8, -9 and PARP. Cells were treated with various concentrations of HI-TOPK-032. At $48 \mathrm{~h}$ of treatment, cells were collected, and then proteins were extracted and analyzed by western blot analysis. (E) Activated caspases were evaluated using Colorimetric Caspase Assay kits in cells treated with HI-TOPK-032 for $48 \mathrm{~h}$. Values for fold induction of signaling (HI-TOPK-032-treated cells/untreated cells) are indicated. Data are the means \pm SD of triplicate cultures. ${ }^{*} \mathrm{P}<0.005$ and ${ }^{* *} \mathrm{P}<0.001$, vs. vehicle-treated control.

induced by HI-TOPK-032 were examined using microscopy. The cells treated with HI-TOPK-032 for $48 \mathrm{~h}$ demonstrated morphological characteristics of apoptosis, such as chromatin condensation and nuclear fragmentation (Fig. 3A). Next, the induction of apoptosis by HI-TOPK-032 was measured using three commonly used assays: APO2.7 staining (Fig. 3B and C), the cleavage of caspases (Fig. 3D) and the activation of caspases (Fig. 3E). The mitochondrial membrane antigen, APO2.7, is known to be expressed during apoptosis (18). Treatment with HI-TOPK-032 resulted in an increase in the proportion of APO2.7-positive apoptotic cells in a dose-dependent manner (Fig. 3B and C). Western blots of the cells treated with HI-TOPK-032 revealed that apoptosis was accompanied by an increase in the cleavage of caspase- $3,-8,-9$ and PARP, a substrate for caspase-3 (Fig. 3D). The activation of caspase-3, -8 and -9 was also detected in the cells treated with $2.5 \mu \mathrm{M}$ of HI-TOPK-032 (Fig. 3E).

HI-TOPK-032 induces apoptosis and $G_{I}$ cell cycle arrest. To examine the effects of HI-TOPK-032 on cell cycle progression, cell cycle analysis was performed on the cells. The cells were treated with 1.25 or $2.5 \mu \mathrm{M}$ of HI-TOPK-032 for $24-48 \mathrm{~h}$.
The percentages of cells in the sub- $\mathrm{G}_{1}$ phase of the high-dose HI-TOPK-032 $(2.5 \mu \mathrm{M})$ treatment group were higher than those of the control group (Fig. 4A and B). In comparison, the low-dose HI-TOPK-032 $(1.25 \mu \mathrm{M})$ treatment group exhibited a reduced proportion of cells in the $\mathrm{S}$ phase, but an increased proportion of cells in the $\mathrm{G}_{1}$ phase population (Fig. 4A and $\mathrm{C}$ ). These results indicate that high-dose and low-dose HI-TOPK-032 induces the apoptosis of and $\mathrm{G}_{1}$ cell cycle arrest in HTLV-1-infected T-cell lines.

HI-TOPK-032 alters the expression of apoptosis- and cell cycle-related proteins. We assessed the effects of HI-TOPK-032 on the molecular cascades of apoptosis in HUT-102 cells. As shown in Fig. 5, HI-TOPK-032 decreased the expression of the anti-apoptotic proteins, Mcl-1, c-IAP2, XIAP and survivin in the HUT-102 cells. By contrast, HI-TOPK-032 enhanced the expression of pro-apoptotic protein, Bak. It had no significant effects on the Bcl-xL and Bax protein levels. To examine the mechanisms through which HI-TOPK-032 induces $\mathrm{G}_{1}$ cell cycle arrest in the HUT-102 cells, the phosphorylation state of $\mathrm{pRb}$ was evaluated by western blot analysis. HI-TOPK-032 decreased the levels of the phosphorylated forms of $\mathrm{pRb}$, and 
A

\section{HI-TOPK-032}

$(\mu \mathrm{M})$

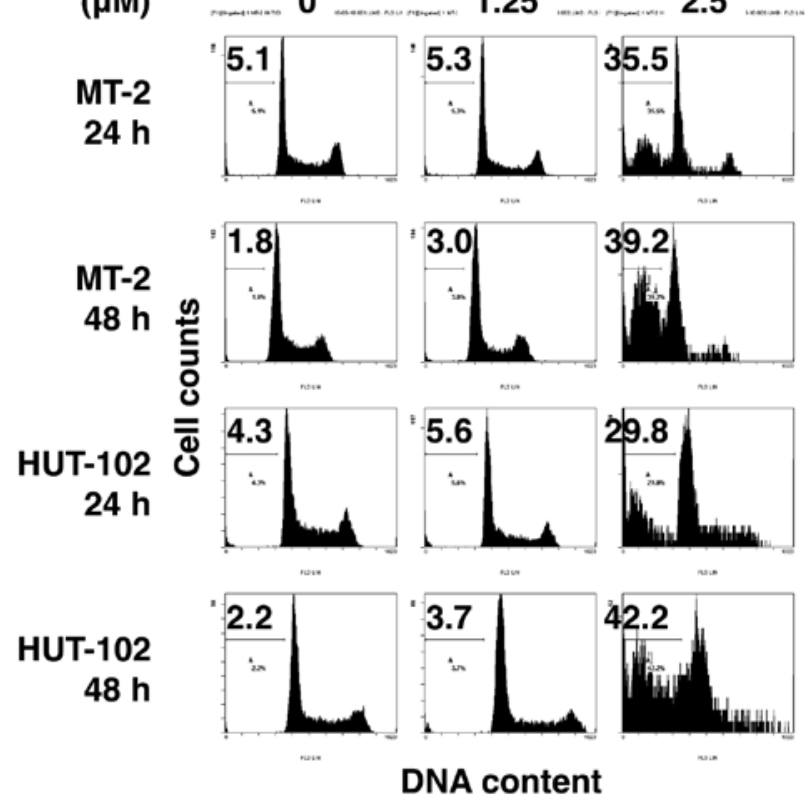

B
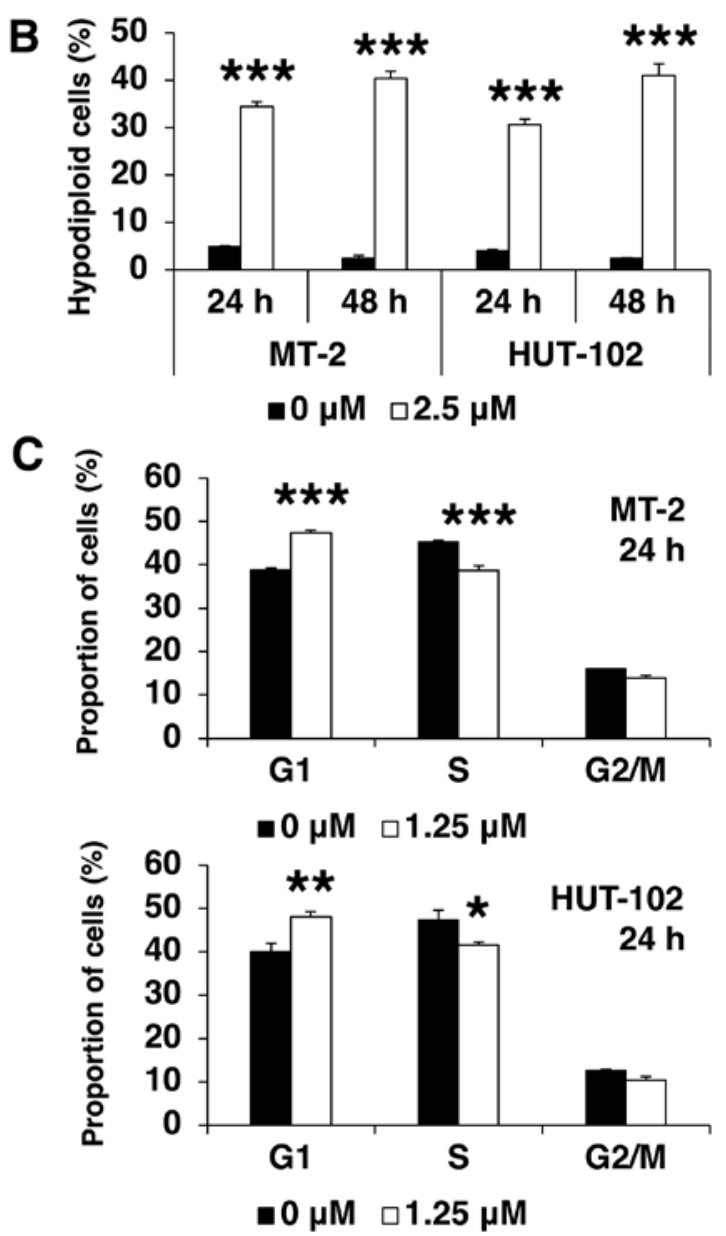

Figure 4. Cell cycle analysis of cells treated with 1.25 or $2.5 \mu \mathrm{M}$ of HI-TOPK-032 for 24-48 h. (A) Representative histograms showing the percentages of cells in the sub- $\mathrm{G}_{1}$ phase. Quantitative assessment of (B) hypodiploid cells among MT-2 and HUT-102 at the indicated two time-points, and (C, top panel) MT-2 and (C, bottom panel) HUT-102 at $24 \mathrm{~h}$ in the $\mathrm{G}_{1}, \mathrm{~S}$ and $\mathrm{G}_{2} / \mathrm{M}$ phase. ${ }^{*} \mathrm{P}<0.05,{ }^{* *} \mathrm{P}<0.005$ and ${ }^{* * *} \mathrm{P}<0.001$, vs. vehicle-treated control.

altered the hyperphosphorylated form to a hypophosphorylated form of $\mathrm{pRb}$ (Fig. 5). Next, we examined the expression of CDK6 to clarify $\mathrm{pRb}$ phosphorylation. Treatment with HI-TOPK-032 decreased the expression of CDK6 (Fig. 5).

Effects of HI-TOPK-032 on the transcription factors, $N F-\kappa B$ and $A P-1$. Transcription factors are proteins that bind at a specific promoter region of the DNA and regulate the expression of various genes. NF- $\mathrm{BB}$ and AP-1 are closely linked with cell survival, proliferation and transformation. Therefore, they are important targets for therapeutic intervention in ATLL (3). Notably, Mcl-1, c-IAP2, XIAP, survivin and CDK6 are NF- $\mathrm{B}-$ regulated gene products (19-23). As shown in Fig. 6A, the DNA-binding of NF- $\kappa$ B and AP-1 was observed in the HUT-102 and MT-2 cells. These binding reactions were specific since cold competitors, but not unrelated oligonucleotides, competed with each DNA-binding activity (Fig. 6A, lanes 2 and 3). The components of NF- $\kappa \mathrm{B}$ and AP-1 DNA-binding complexes were analyzed with specific antibodies against $5 \mathrm{NF}-\kappa \mathrm{B}$ family proteins and 7 AP-1 family proteins. The activated complexes of NF- $\kappa$ B and AP-1 consisted of p50/p65/c-Rel/RelB (Fig. 6A, lanes 4-6 and 8) and JunB/JunD (Fig. 6A, lanes 9 and 10), respectively. We investigated whether HI-TOPK-032 inhibits the constitutive NF- $\kappa \mathrm{B}$ and AP-1 activation in HTLV-1infected T-cell lines. HI-TOPK-032 reduced the DNA-binding of NF- $\mathrm{NB}$ and AP-1 in a dose-dependent manner (Fig. 6B). Next, we examined the effect of HI-TOPK-032 on JunB/JunD expression, as JunB/JunD are functional components of AP-1 in HTLV-1-infected T-cell lines. Western blot analysis revealed that HI-TOPK-032 inhibited the AP-1 signaling pathway through the suppression of JunB/JunD protein levels (Fig. 5, right panel).

Effects of HI-TOPK-032 on $N F-\kappa B$ and Akt signaling pathways. In the unstimulated state, $\mathrm{NF}-\kappa \mathrm{B}$ is sequestered in the cytoplasm by binding to $\mathrm{I} \kappa \mathrm{B} \alpha$. In response to a variety of stimuli including viruses, the IKK complex comprised of IKK $\alpha / \mathrm{IKK} \beta / \mathrm{IKK} \gamma$ is activated, and phosphorylates $\mathrm{I} \kappa \mathrm{B} \alpha$, which is sequentially ubiquitinated and subjected to proteasomal degradation (24). As PBK/TOPK was identified as a novel upstream kinase of $\mathrm{I} \kappa \mathrm{B} \alpha$ regulating $\mathrm{NF}-\kappa \mathrm{B}(25)$, we examined whether HI-TOPK-032 affects I $\mathrm{B} \alpha$ phosphorylation. HI-TOPK-032 inhibited the phosphorylation and degradation of I $\kappa \mathrm{B} \alpha$ (Fig. 5). In addition, the inhibition of PBK/TOPK by HI-TOPK-032 led to a slight decrement in the total IKK $\beta$ levels and a significant reduction in phosphorylated IKK $\alpha / \beta$ levels. The phosphoinositide 3-kinase (PI3K)-Akt signal is a component of a pathway important for cell survival and growth during carcinogenesis, and Akt utilizes IKKs for the activation of NF- $\mathrm{BB}$ (26). The tumor suppressor, PTEN, dephosphorylates 


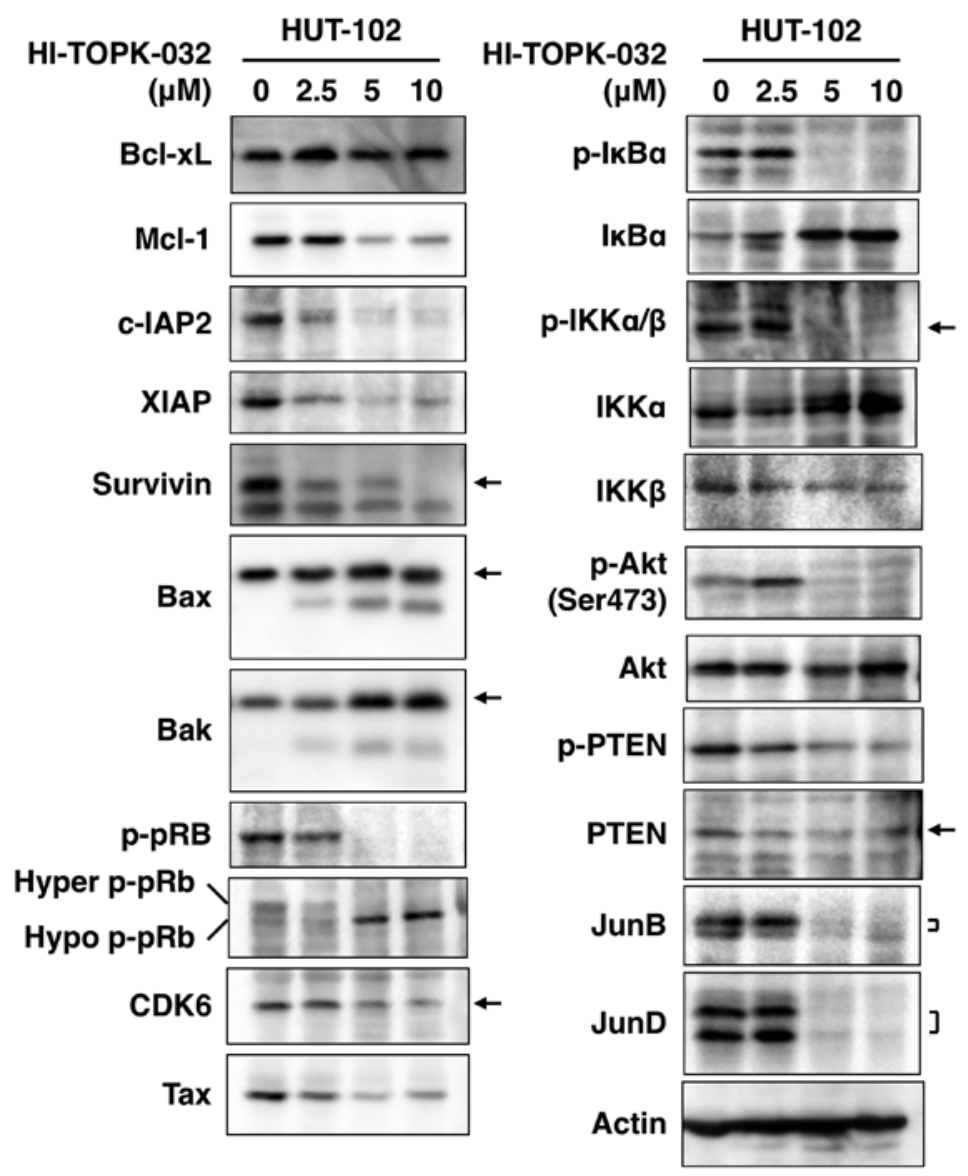

Figure 5. HI-TOPK-032 alters the expression levels of cell cycle- and apoptosis-regulated proteins, phosphorylated PTEN-Akt and IKK $\alpha / \beta$-IкB $\alpha$, and JunB/ JunD proteins. HUT-102 cells were treated with various concentrations of HI-TOPK-032 for $48 \mathrm{~h}$ prior to western blot analysis using the indicated specific antibodies. For all blots, actin was used as the loading control.
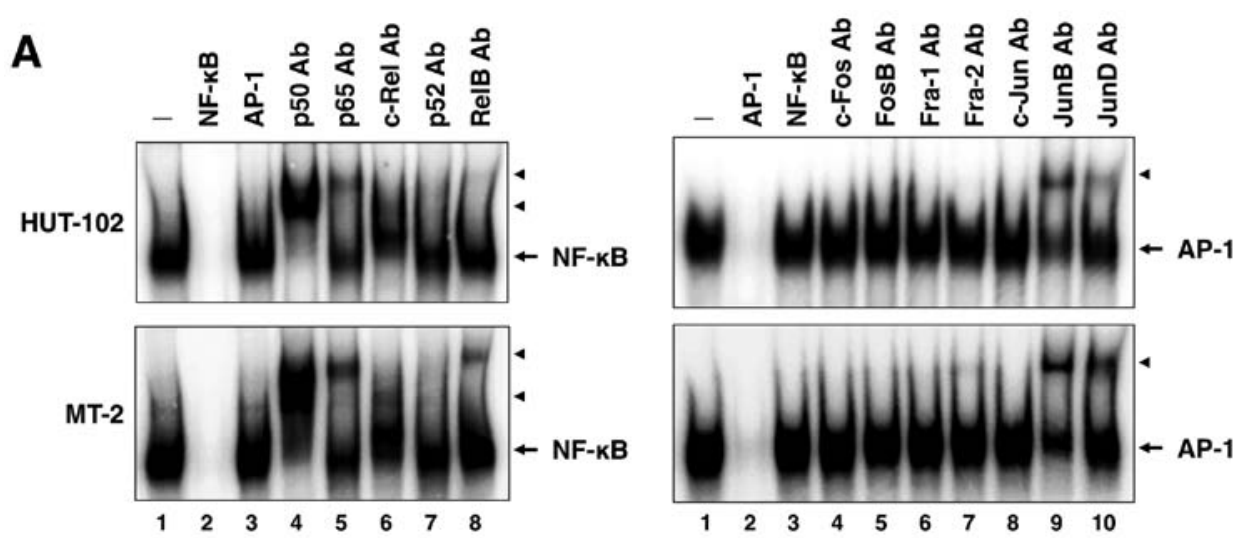

B

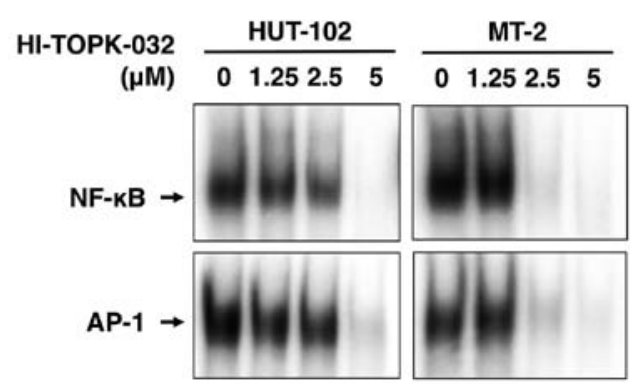

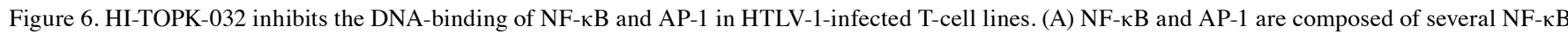
and AP-1 subunits, respectively. Nuclear extracts from untreated cells were incubated with the indicated unlabeled NF-kB or AP-1 oligo probe (lanes 2 and 3), and antibodies (lanes 4-8 in left panels; lanes 4-10 in right panels). They were then assayed for DNA-binding of NF-kB and AP-1 by EMSA. Ab, antibody. Arrows and arrowheads indicate a specific complex and a supershifted band, respectively. (B) HUT-102 and MT-2 cells were treated with various concentrations of HI-TOPK-032 for $24 \mathrm{~h}$. The nuclear extracts were assayed for DNA-binding of NF-kB and AP-1 by EMSA. Arrows indicate a specific complex. 
Table II. Genes with changes in expression exceeding 20-fold found by microarray in HUT-102 and MT-2 cells evaluated following exposure to $5 \mu \mathrm{M}$ of HI-TOPK-032 for $24 \mathrm{~h}$.

\begin{tabular}{lcrr}
\hline Symbol & Upregulated genes & HUT-102 cells & MT-2 cells \\
\hline IFIT2 & Interferon-induced protein with tetratricopeptide repeats 2 & 236 \\
IFIT3 & Interferon-induced protein with tetratricopeptide repeats 3 & 94 & 63 \\
IFIT1 & Interferon-induced protein with tetratricopeptide repeats 1 & 59 & 49 \\
RNF150 & Ring finger protein 150 & 51 & 26 \\
BCR & Breakpoint cluster region & 47 & 113 \\
OASL & 2'-5'-oligoadenylate synthetase-like & 43 & 79 \\
RAP1GAP & RAP1 GTPase activating protein & 35 & 109 \\
GPR182 & G protein-coupled receptor 182 & 31 & 97 \\
EGFR & Epidermal growth factor receptor & 30 & 82 \\
RIMS3 & Regulating synaptic membrane exocytosis 3 & 29 & 50 \\
SLC51B & Solute carrier family 51, beta subunit & 29 & 126 \\
GPR179 & G protein-coupled receptor 179 & 28 & 91 \\
MAGEB6 & Melanoma antigen family B,6 & 28 & 90 \\
HSPA6 & Heat shock 70 kDa protein 6 (HSP70B') & 28 & 43 \\
BICC1 & BicC family RNA binding protein 1 & 28 & 86 \\
HERC6 & HECT and RLD domain containing E3 ubiquitin protein ligase family member 6 & 27 & 35 \\
KRT79 & Keratin 79, type II & 26 & 85 \\
IFI44 & Interferon-induced protein 44 & 25 & 24 \\
RPA4 & Replication protein A4, 30 kDa & 23 & 65 \\
REP15 & RAB15 effector protein & 23 & 157 \\
SPEN & Spen family transcriptional repressor & 23 & 104 \\
CD86 & CD86 molecule & 23 & 68 \\
CCDC66 & Coiled-coil domain containing 66 & 22 & 87 \\
LRRC2 & Leucine rich repeat containing 2 & 21 & 54 \\
\hline & & &
\end{tabular}

phosphatidylinositol 3,4,5-triphosphate (PIP3) to PI(4,5)P2, and opposes the PI3K-Akt signaling (27). The loss of the expression/activity of PTEN is among the most frequently occurring in cancer (27). ATLL cells do not harbor genetic changes in PTEN, but express high levels of PTEN that is highly phosphorylated (28). Its phosphorylation maintains PTEN in an inactive form (29). It has been suggested that PBK/TOPK promotes Akt activation by inducing PTEN phosphorylation (30). Thus, we hypothesized that PBK/TOPK may regulate the PTEN-Akt pathway in ATLL. The decreased PTEN phosphorylation levels upon HI-TOPK-032 treatment were associated with a decreased Akt phosphorylation (Fig. 5), suggesting that the PBK/TOPK-mediated phosphorylation of PTEN may lead to PTEN inactivation and Akt activation in ATLL. Tax activates NF- $\kappa B$ by interacting with IKK $\gamma(5)$. In addition, Tax activates Akt by inhibition of PTEN (31). We then examined the effect of HI-TOPK-032 on Tax expression. As shown in Fig. 5, the amount of Tax in HUT-102 cells decreased progressively with the increasing concentrations of HI-TOPK-032. Therefore, Tax may also be a target of HI-TOPK-032.

HI-TOPK-032 induces IFIT1-3 expression. To address the vital mechanisms of HI-TOPK-032-induced cell death, we also used DNA microarray analysis and compared the gene expression profiles of treated and untreated cells. We selected the evaluation of only genes that were upregulated by $>20$-fold (see the list of these genes in Table II). One notable conclusion that can be drawn from Table II is that genes associated with IFN regulation (IFIT1-3, OASL and IFI44) are the most highly upregulated by HI-TOPK-032 in two cell lines. IFIT1 plays a key role in suppression of growth and promotion of apoptosis of cancer cells (32). IFIT2 promotes apoptosis through a mitochondrial pathway dependent on the action of Bcl-2 proteins (33). Bax and Bak are required for apoptosis in response to IFIT2 (33). IFIT3 is also an anti-proliferative IFN-induced protein (34). It was important to confirm the microarray results with RT-PCR. Similar to the results of the microarray analysis, the IFITI and 2 genes were overexpressed in the HUT-102 and MT-2 cells (Fig. 7A). The IFIT1-3 protein levels were also increased in the HUT-102 cells treated with HI-TOPK-032 (Fig. 7B). These results suggest the involvement of IFITs in HI-TOPK-032-induced apoptosis. In addition, similar to the results of western blot analysis, the downregulation of c-IAP2, survivin and Tax, and the upregulation of Bak were confirmed by RT-PCR (Fig. 7A). The HTLV-1 basic leucine zipper factor (HBZ), which is encoded by the minus-strand of the provirus, is linked to oncogenic transformation in addition to Tax (35). Thus, we examined the level of HBZ expression. However, HI-TOPK-032 did not affect the expression of HBZ (Fig. 7A). 
A

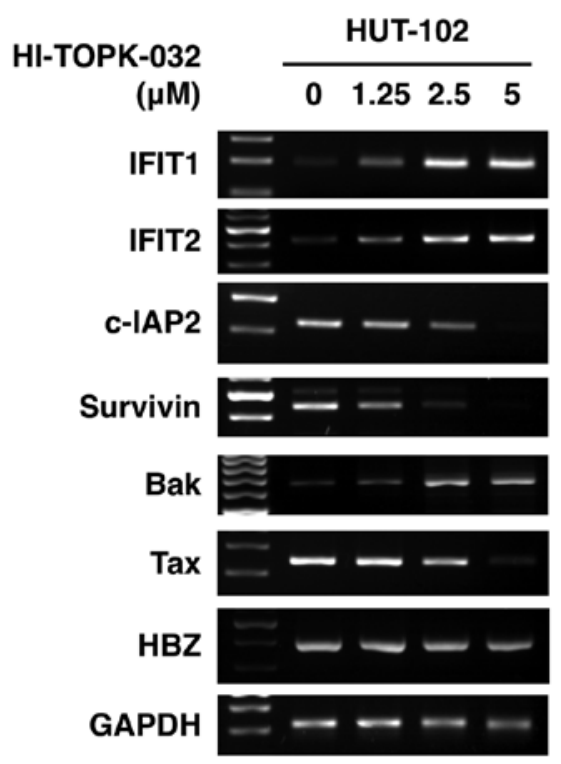

B

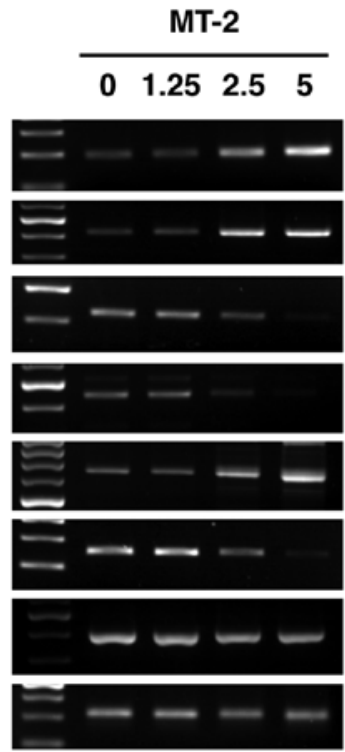

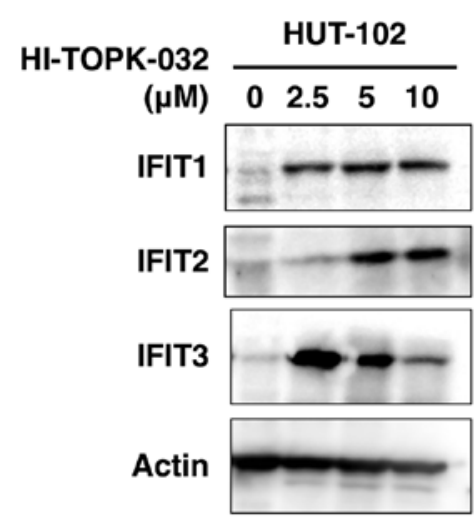

Figure 7. HI-TOPK-032 induces the expression of IFITs. (A) RT-PCR analysis of apoptosis-regulated genes and viral genes in HUT-102 and MT-2 cells treated with various concentrations of HI-TOPK-032 for $24 \mathrm{~h}$. GAPDH was used as the loading control. (B) Western blot analysis of IFIT expression in HUT-102 cells treated with various concentrations of HI-TOPK- 032 for $48 \mathrm{~h}$. Actin was used as the loading control.

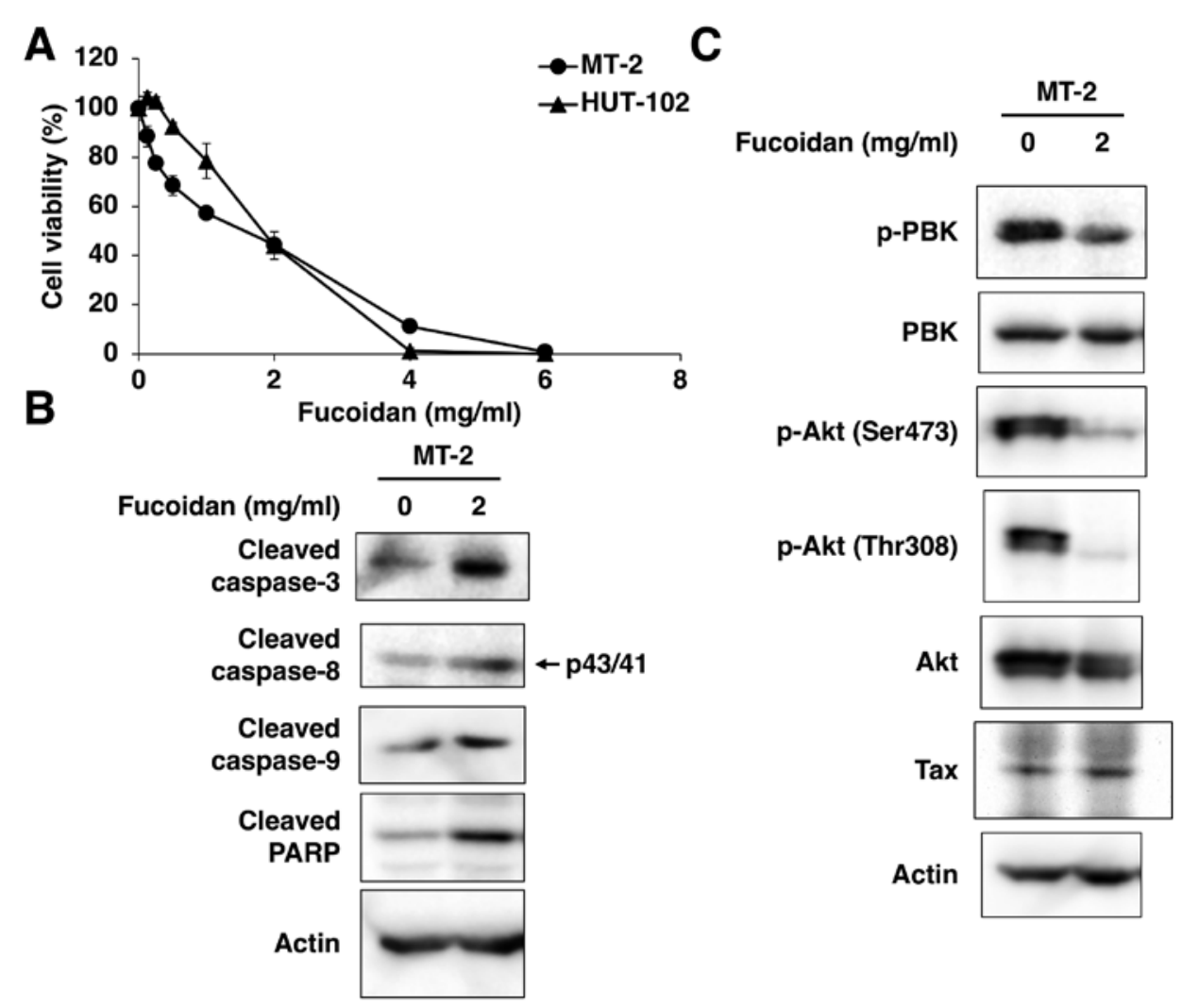

Figure 8. PBK/TOPK is the target of fucoidan. (A) Cytotoxic effects of fucoidan on HTLV-1-infected T-cell lines. WST-8 assay was used after treatment of cells with fucoidan for $48 \mathrm{~h}$. The experiment was performed in triplicate. Data are the means \pm SD. (B) Effect of fucoidan on cleavage of caspase-3, $-8,-9$ and PARP. MT-2 cells were treated with $2 \mathrm{mg} / \mathrm{ml}$ of fucoidan for $72 \mathrm{~h}$, and western blot analysis was performed. (C) Fucoidan inhibits PBK/TOPK-Akt signal transduction but not Tax expression in MT-2 cells, as determined by western blot analysis with specific antibodies. MT-2 cells were treated with $2 \mathrm{mg} / \mathrm{ml}$ of fucoidan for $72 \mathrm{~h}$.

Effects of fucoidan on HTLV-1-infected T-cell lines. We previously reported that fucoidan, a sulfated polysaccharide isolated from brown algae Cladosiphon okamuranus Tokida, induced apoptosis through the suppression of $\mathrm{NF}-\kappa \mathrm{B}$ and AP-1 in HTLV-1-infected T-cell lines (36). A recent study indicated that fucoidan directly interacts with PBK/TOPK and 
A

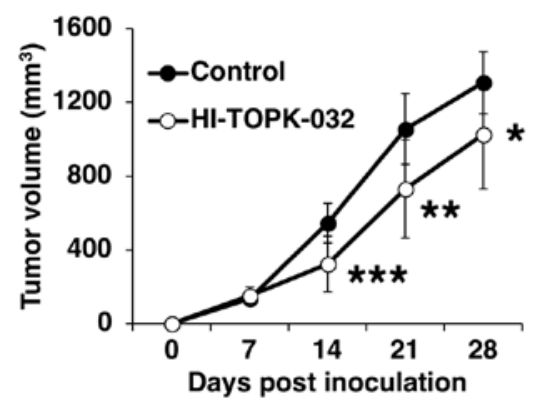

D
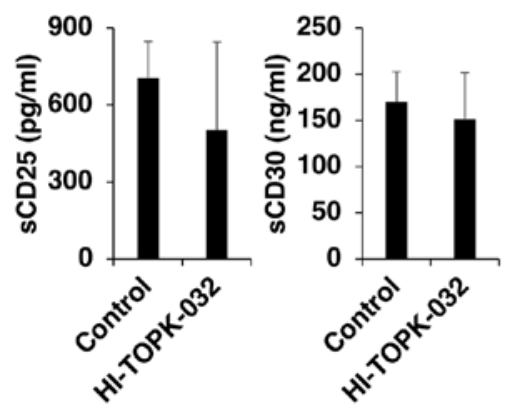

B

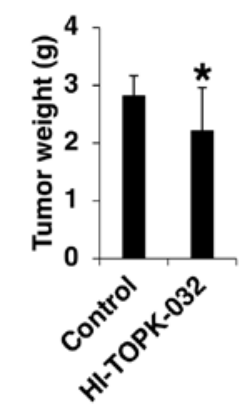

E
C

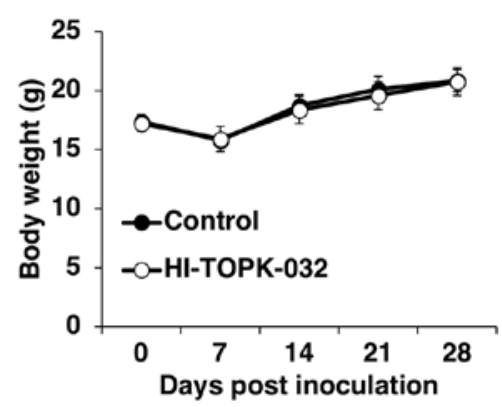

TUNEL

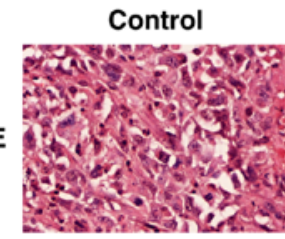
HI-TOPK-032

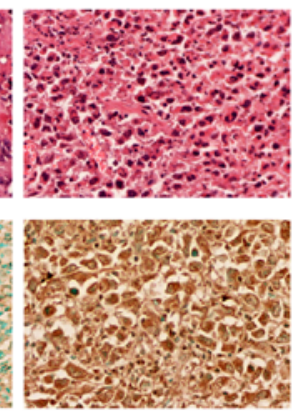

Figure 9. HI-TOPK-032 inhibits xenograft tumor growth. (A) HI-TOPK-032 suppresses ATLL tumor growth. HUT-102 cells were inoculated subcutaneously into the post-auricular region of mice. Mice were injected intraperitoneally with HI-TOPK-032 (12.5 mg/kg) or vehicle 5 times a week for 28 days, then monitored until 28 days after HUT-102 cell inoculation. Tumor volume was calculated. ${ }^{*} \mathrm{P}<0.05,{ }^{* *} \mathrm{P}<0.01$ and ${ }^{* * *} \mathrm{P}<0.005$, vs. vehicle-treated control. (B) Tumors were extracted after 28 days of cell inoculation. Tumor weights of the HI-TOPK-032-treated group were significantly smaller than the vehicle control group. ${ }^{*} \mathrm{P}<0.05$ vs. vehicle-treated control. (C) HI-TOPK-032 had no effect on mouse body weight. Body weights of treated and untreated group of mice were measured once a week. (D) Serum concentrations of sCD25 and sCD30 in mice. Data are the means \pm SD. (E) Cell apoptosis in tumor tissues determined by H\&E and TUNEL staining. Magnification, x800.

inhibits its kinase activity (37). As shown in Fig. 8A, fucoidan decreased the viability of HTLV-1-infected T-cell lines in a dose-dependent manner. Furthermore, fucoidan increased the cleavage of caspase-3, $-8,-9$ and PARP in the MT-2 cells (Fig. 8B). Based on these results, we investigated whether fucoidan influences the PBK/TOPK-Akt signaling axis. As expected, the decreased phosphorylation of PBK/TOPK and downregulation of kinase Akt was observed in the cells treated with fucoidan (Fig. 8C). On the other hand, the expression of Tax was not affected by fucoidan.

HI-TOPK-032 inhibits ATLL tumor growth in a xenograft mouse model. In addition to the above-mentioned experiments in the cultured cells, we examined the antitumor activity of HI-TOPK-032 in mice. HUT-102 cells were inoculated subcutaneously into the post-auricular region of SCID mice. The mice were injected intraperitoneally with either the vehicle or HI-TOPK-032 at $12.5 \mathrm{mg} / \mathrm{kg} 5$ times a week over a period of 4 weeks. Multiple tumors were not observed in any of the mice. The maximum diameter of a single tumor and the maximum tumor volume observed were $18 \times 18 \times 5 \mathrm{~mm}$ and $1,620 \mathrm{~mm}^{3}$, respectively. Treatment of mice with HI-TOPK-032 significantly inhibited HUT-102 tumor volume and weight compared with the vehicle-treated group (Fig. 9A and B). In addition, mice appeared to tolerate the treatment with HI-TOPK-032 without any overt signs of toxicity or significant loss of body weight (16.4-18.5 and 19.3-22.5 g upon purchase and upon sacrifice, respectively), similar to the vehicle-treated group
(16.4-18.2 and 19.5-21.6 $\mathrm{g}$ upon purchase and upon sacrifice) (Fig. 9C). These results confirmed that HI-TOPK-032 inhibited tumor growth through the inhibition of PBK/TOPK. Next, we used ELISA to determine the circulating levels of surrogate tumor markers sCD25 (38) and sCD30 (39) secreted by HUT-102 tumor xenografts. The HI-TOPK-032-treated mice exhibited a 29 and $11 \%$ decrease in sCD25 and sCD30 levels, respectively, compared with the control group, although the observed changes in these levels were not statistically significant (Fig. 9D).

H\&E staining revealed a significant increase in apoptosis in mice treated with HI-TOPK-032 compared with the control group. Apoptosis was characterized by cytoplasmic condensation, chromatin hyperchromatism and condensation, and nuclear fragmentation. TUNEL assay confirmed these findings and demonstrated increased apoptosis signals in HI-TOPK-032-treated tumors (Fig. 9E). These findings support the interpretation that the observed decline in tumor growth in the HI-TOPK-032-treated tumors in vivo was caused by an increase in apoptosis.

\section{Discussion}

The serine-threonine kinase PBK/TOPK contributes to various oncogenic cellular functions, including tumor cell proliferation and anti-apoptotic effects (6-10). Thus, it is a potential target for the development of novel anticancer agents. In this study, the overexpression and phosphorylation of PBK/TOPK 


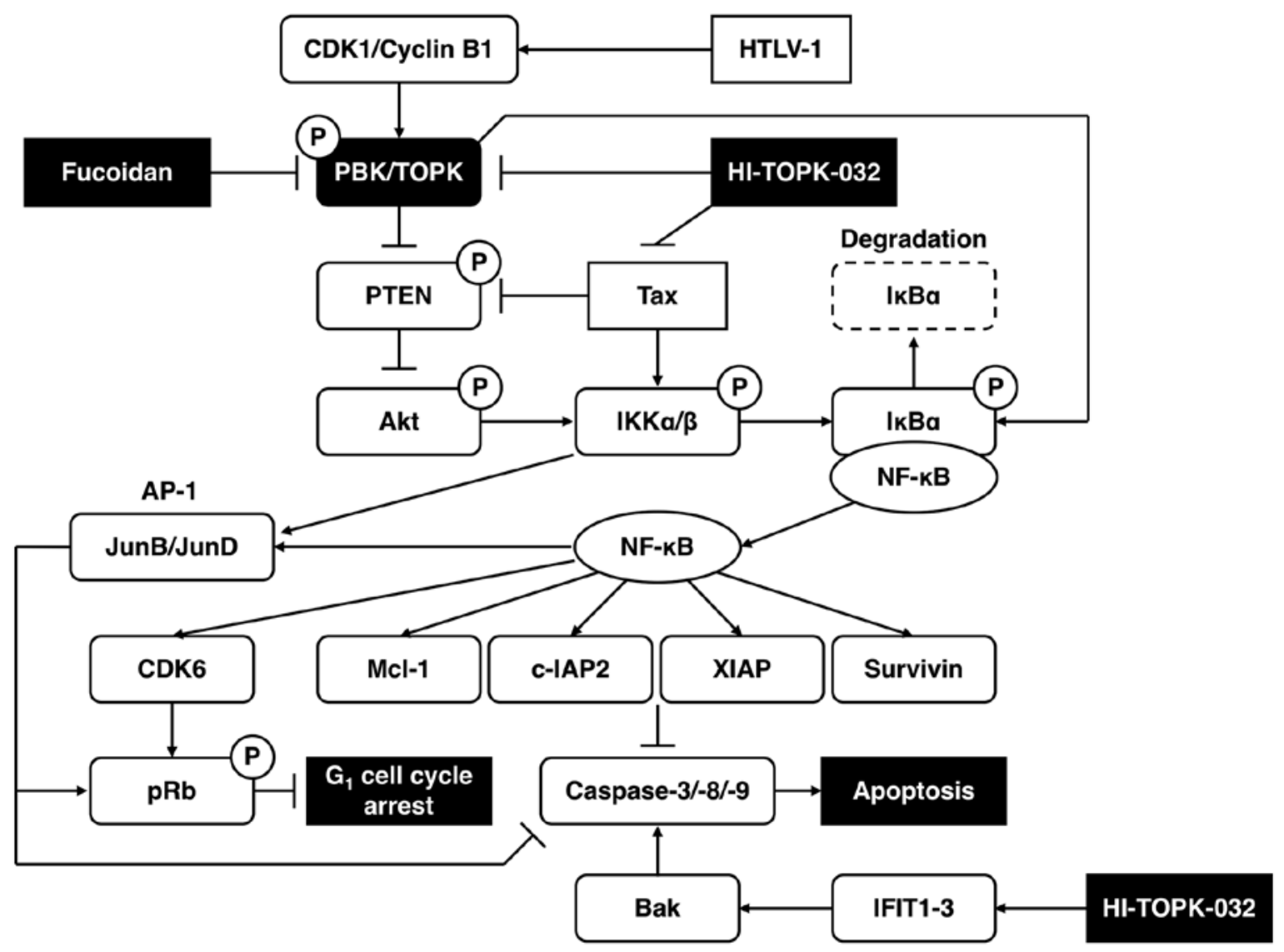

Figure 10. Proposed model of the action of HI-TOPK-032 and fucoidan.

were observed in HTLV-1-infected T-cell lines. In addition, HTLV-1 infection upregulated PBK/TOPK expression in PBMCs, suggesting that this kinase increases the rate of mitosis and expands malignant T cells. CDK1/cyclin B1, which phosphorylates PBK/TOPK during mitosis, was also overexpressed, suggesting that constitutive expression of CDK1/ cyclin B1 activates PBK/TOPK in HTLV-1-infected T-cell lines. Thus, we addressed the biological role of BPK/TOPK in ATLL through the inhibition of its kinase activity using HI-TOPK-032. HI-TOPK-032 strongly suppressed the growth of HTLV-1-infected T cells and induced apoptosis, compared with normal PBMCs, suggesting that PBK/TOPK is important in the proliferation and survival of HTLV-1-infected T-cell lines.

Previous studies have demonstrated that PBK/TOPK directly interacts with, phosphorylates and inactivates PTEN, which in turn activates Akt (30). Therefore, we investigated whether HI-TOPK-032 affects the phosphorylation of PTEN and Akt in HTLV-1-infected T-cell lines. Indeed, the results revealed that HI-TOPK-032 inhibited the phosphorylation of PTEN and Akt. Although the loss of tumor suppressor N-myc downstream-regulated gene 2 reportedly enhances phosphorylation of PTEN in ATLL (28), PBK/TOPK could also participate in PTEN phosphorylation.

3-Phosphoinositide-dependent protein kinase 1 (PDK1), an immediate downstream mediator of PI3K, can directly phosphorylate IKK $\beta$ and activate $N F-\kappa B$ signaling (40). In addition, Akt also activates IKK $\alpha$ (41-43). On the other hand, PBK/TOPK directly interacts with and phosphorylates $\mathrm{I} \kappa \mathrm{B} \alpha$, leading to $\mathrm{NF}-\kappa \mathrm{B}$ activation (25). Our results revealed that HI-TOPK-032 suppressed the phosphorylation of IKK $\alpha / \beta$ and $\mathrm{I} \kappa \mathrm{B} \alpha$, suggesting that PBK/TOPK seems to activate $\mathrm{NF}-\kappa \mathrm{B}$ through direct phosphorylation of $\mathrm{I} \kappa \mathrm{B} \alpha$ or indirect activation of the PI3K-Akt-IKK signaling pathway by inactivation of PTEN. Furthermore, the NF- $\kappa$ B elements contribute to the induction of JunB (44). AP-1 is also a downstream target of Akt-IKK $\alpha$ (43). In addition to HI-TOPK-032, fucoidan, which exhibits anti-ATLL activity, also dephosphorylated PBK/TOPK as well as Akt. This result, and our previous finding of fucoidan-induced inactivation of $N F-\kappa B$ and AP-1 (36), supports the anti-ATLL efficacy of fucoidan through its targeting of PBK/TOPK. Collectively, these results emphasize the potential of targeting PBK/TOPK to inactivate Akt and NF- $\kappa \mathrm{B}$ that are required for AP-1 activation, with resultant dysregulation of various survival cell signaling pathways in ATLL (Fig. 10).

Microarray analysis demonstrated that HI-TOPK-032 upregulated the IFN-stimulated genes, IFIT1-3, and these results were confirmed by RT-PCR and western blot analyses. IFIT1-3 are anti-proliferative and pro-apoptotic proteins (32-34). IFIT2 can form a multiprotein complex with itself and IFIT1 and IFIT3 through the mitochondrial pathway to induce apoptosis (33). HI-TOPK-032 also induced the expression of pro-apoptotic protein Bak, which is required for apoptosis in response to IFIT2 (33). The induction of IFIT1-3 and Bak in HTLV-1-infected T-cell lines exposed to HI-TOPK-032 suggests that, in addition to the suppression of cell survival signals, HI-TOPK-032 can probably inhibit the 
progression of ATLL by inducing these pro-apoptotic proteins and enhancing apoptosis (Fig. 10). Endogenously derived danger signals, as a consequence of cell death, are referred to as damage-associated molecular patterns (DAMPs). Specific chemotherapies can activate an altered-self mimicry orchestrated by detection of self-double-stranded RNA, resulting in cancer cell-autonomous production of type I IFNs that elicit anticancer effects (45). IFN-stimulated genes may be upregulated by DAMPs from dying cells and may not be directly related to the death of cells.

Importantly, the administration of HI-TOPK-032 at a dose of $12.5 \mathrm{mg} / \mathrm{kg}$ as an experimental therapy led to a reduction in tumor growth in our mouse model, and that such effect was free of any side effects/toxicity. Notably, H\&E and TUNEL staining of HI-TOPK-032-treated tumors showed increased number of apoptotic cells. These observations in our mouse model confirm the functional importance of PBK/TOPK in the growth and survival of ATLL cells.

In conclusion, HI-TOPK-032, a specific PBK/TOPK inhibitor, decreased the growth and survival of HTLV-1-infected T-cell lines both in vitro and in vivo. Our findings should be useful for further development of novel chemotherapeutics for ATLL based on targeting PBK/TOPK.

\section{Acknowledgements}

The authors would like to thank Fujisaki Cell Center, Hayashibara Biochemical Laboratories, Inc. (Okayama, Japan) for providing C5/MJ,HUT-102 and MT-1, Dr Naoki Yamamoto (Tokyo Medical and Dental University, Tokyo, Japan) for providing MT-2 and MT-4, Dr Diane Prager (UCLA School of Medicine, Los Angeles, CA, USA) for providing SLB-1, Dr Michiyuki Maeda (Kyoto University, Kyoto, Japan) for providing ED-40515(-), Dr Masahiro Fujii (Niigata University, Niigata, Japan) for providing TL-OmI, Kanehide Bio Co. (Okinawa, Japan) for providing fucoidan, and Dr Yuetsu Tanaka for providing Tax antibody. Recombinant human IL-2 was kindly provided by Takeda Pharmaceutical Company Ltd. (Osaka, Japan).

\section{Funding}

This study was supported in part by JSPS KAKENHI Grant number 15K18414. This study was funded by Kanehide Bio Co.

\section{Availability of data and materials}

All data generated or analyzed during this study are included in this published article.

\section{Authors' contributions}

CI and NM were responsible for the study design, original article drafting and editing, data acquisition and data analysis. MS was responsible for data acquisition and data analysis. All authors have read and approved this manuscript.

\section{Ethics approval and consent to participate}

Not applicable.

\section{Consent for publication}

Not applicable.

\section{Competing interests}

The authors declare that they have no competing interests.

\section{References}

1. Ishitsuka $\mathrm{K}$ and Tamura $\mathrm{K}$ : Human T-cell leukaemia virus type I and adult T-cell leukaemia-lymphoma. Lancet Oncol 15: e517-e526, 2014.

2. Hall WW and Fujii M: Deregulation of cell-signaling pathways in HTLV-1 infection. Oncogene 24: 5965-5975, 2005.

3. Mori N: Cell signaling modifiers for molecular targeted therapy in ATLL. Front Biosci 14: 1479-1489, 2009.

4. Watanabe T: Adult T-cell leukemia: Molecular basis for clonal expansion and transformation of HTLV-1-infected T cells. Blood 129: 1071-1081, 2017.

5. Currer R, Van Duyne R, Jaworski E, Guendel I, Sampey G, Das R, Narayanan A and Kashanchi F: HTLV tax: A fascinating multifunctional co-regulator of viral and cellular pathways. Front Microbiol 3: 406, 2012.

6. Abe Y, Matsumoto S, Kito K and Ueda N: Cloning and expression of a novel MAPKK-like protein kinase, lymphokine-activated killer T-cell-originated protein kinase, specifically expressed in the testis and activated lymphoid cells. J Biol Chem 275: 21525-21531, 2000.

7. Simons-Evelyn M, Bailey-Dell K, Toretsky JA, Ross DD, Fenton R, Kalvakolanu D and Rapoport AP: PBK/TOPK is a novel mitotic kinase which is upregulated in Burkitt's lymphoma and other highly proliferative malignant cells. Blood Cells Mol Dis 27: 825-829, 2001.

8. Nandi A, Tidwell M, Karp J and Rapoport AP: Protein expression of PDZ-binding kinase is up-regulated in hematologic malignancies and strongly down-regulated during terminal differentiation of HL-60 leukemic cells. Blood Cells Mol Dis 32: 240-245, 2004

9. Gaudet S, Branton D and Lue RA: Characterization of PDZ-binding kinase, a mitotic kinase. Proc Natl Acad Sci USA 97: 5167-5172, 2000 .

10. Matsumoto S, Abe Y, Fujibuchi T, Takeuchi T, Kito K, Ueda N, Shigemoto K and Gyo K: Characterization of a MAPKK-like protein kinase TOPK. Biochem Biophys Res Commun 325: 997-1004, 2004.

11. Shats I, Gatza ML, Chang JT, Mori S, Wang J, Rich J and Nevins JR: Using a stem cell-based signature to guide therapeutic selection in cancer. Cancer Res 71: 1772-1780, 2011.

12. Takeda K, Tomimori K, Kimura R, Ishikawa C, Nowling TK and Mori N: Anti-tumor activity of fucoidan is mediated by nitric oxide released from macrophages. Int $\mathrm{J}$ Oncol 40: 251-260, 2012.

13. Tanaka Y, Yoshida A, Takayama Y, Tsujimoto H, Tsujimoto A, Hayami $M$ and Tozawa $\mathrm{H}$ : Heterogeneity of antigen molecules recognized by anti-tax 1 monoclonal antibody Lt- 4 in cell lines bearing human $\mathrm{T}$ cell leukemia virus type I and related retroviruses. Jpn J Cancer Res 81: 225-231, 1990.

14. Kimura R, Senba M, Cutler SJ, Ralph SJ, Xiao G and Mori N: Human $\mathrm{T}$ cell leukemia virus type I tax-induced IкB- $\zeta$ modulates tax-dependent and tax-independent gene expression in T cells. Neoplasia 15: 1110-1124, 2013.

15. Mori $\mathrm{N}$ and Prager D: Transactivation of the interleukin-1alpha promoter by human T-cell leukemia virus type I and type II Tax proteins. Blood 87: 3410-3417, 1996.

16. Inoue J, Seiki M, Taniguchi T, Tsuru S and Yoshida M: Induction of interleukin 2 receptor gene expression by $\mathrm{p} 40 \mathrm{x}$ encoded by human T-cell leukemia virus type 1. EMBO J 5: 2883-2888, 1986.

17. Kim DJ, Li Y, Reddy K, Lee M-H, Kim MO, Cho Y-Y, Lee S-Y, Kim J-E, Bode AM and Dong Z: Novel TOPK inhibitor HI-TOPK-032 effectively suppresses colon cancer growth. Cancer Res 72: 3060-3068, 2012.

18. Zhang C, Ao Z, Seth A and Schlossman SF: A mitochondrial membrane protein defined by a novel monoclonal antibody is preferentially detected in apoptotic cells. J Immunol 157: 3980-3987, 1996. 
19. Iwanaga R, Ozono E, Fujisawa J, Ikeda MA, Okamura N, Huang Y and Ohtani K: Activation of the cyclin D2 and cdk6 genes through NF-kappaB is critical for cell-cycle progression induced by HTLV-I Tax. Oncogene 27: 5635-5642, 2008.

20. Kawakami H, Tomita M, Matsuda T, Ohta T, Tanaka Y, Fujii M, Hatano M, Tokuhisa $\mathrm{T}$ and Mori N: Transcriptional activation of survivin through the NF-kappaB pathway by human T-cell leukemia virus type I tax. Int J Cancer 115: 967-974, 2005.

21. Kawakami A, Nakashima T, Sakai H, Urayama S, Yamasaki S, Hida A, Tsuboi M, Nakamura $\mathrm{H}$, Ida $\mathrm{H}$, Migita $\mathrm{K}$, et al: Inhibition of caspase cascade by HTLV-I tax through induction of NF-kappaB nuclear translocation. Blood 94: 3847-3854, 1999.

22. Wäldele K, Silbermann K, Schneider G, Ruckes T, Cullen BR and Grassmann R: Requirement of the human T-cell leukemia virus (HTLV-1) tax-stimulated HIAP-1 gene for the survival of transformed lymphocytes. Blood 107: 4491-4499, 2006.

23. Reuter S, Prasad S, Phromnoi K, Ravindran J, Sung B, Yadav VR, Kannappan R, Chaturvedi MM and Aggarwal BB: Thiocolchicoside exhibits anticancer effects through downregulation of NF- $\kappa \mathrm{B}$ pathway and its regulated gene products linked to inflammation and cancer. Cancer Prev Res (Phila) 3: 1462-1472, 2010

24. Sun S-C and Cesarman E: NF- $\mathrm{BB}$ as a target for oncogenic viruses. Curr Top Microbiol Immunol 349: 197-244, 2011.

25. Park J-H, Yoon D-S, Choi H-J, Hahm D-H and Oh S-M Phosphorylation of $\mathrm{I} \kappa \mathrm{B} \alpha$ at serine 32 by T-lymphokine-activated killer cell-originated protein kinase is essential for chemoresistance against doxorubicin in cervical cancer cells. J Biol Chem 288: 3585-3593, 2013

26. Madrid LV, Mayo MW, Reuther JY and Baldwin AS Jr: Akt stimulates the transactivation potential of the RelA/p65 subunit of NF-kappa B through utilization of the Ikappa B kinase and activation of the mitogen-activated protein kinase p38. J Biol Chem 276: 18934-18940, 2001.

27. Hollander MC, Blumenthal GM and Dennis PA: PTEN loss in the continuum of common cancers, rare syndromes and mouse models. Nat Rev Cancer 11: 289-301, 2011.

28. Nakahata S, Ichikawa T, Maneesaay P, Saito Y,Nagai K, Tamura T, Manachai N, Yamakawa N, Hamasaki M, Kitabayashi I, et al: Loss of NDRG2 expression activates PI3K-AKT signalling via PTEN phosphorylation in ATLL and other cancers. Nat Commun 5: 3393, 2014.

29. Rahdar M, Inoue T, Meyer T, Zhang J, Vazquez $F$ and Devreotes PN: A phosphorylation-dependent intramolecular interaction regulates the membrane association and activity of the tumor suppressor PTEN. Proc Natl Acad Sci USA 106: 480-485, 2009.

30. Shinde SR, Gangula NR, Kavela S, Pandey V and Maddika S: TOPK and PTEN participate in CHFR mediated mitotic checkpoint. Cell Signal 25: 2511-2517, 2013.

31. Cherian MA, Baydoun HH, Al-Saleem J, Shkriabai N, Kvaratskhelia M, Green P and Ratner L: Akt pathway activation by human T-cell leukemia virus type 1 Tax oncoprotein. J Biol Chem 290: 26270-26281, 2015.

32. Zhang J-F, Chen Y, Lin G-S, Zhang J-D, Tang W-L, Huang J-H Chen J-S, Wang X-F and Lin Z-X: High IFIT1 expression predicts improved clinical outcome, and IFIT1 along with MGMT more accurately predicts prognosis in newly diagnosed glioblastoma. Hum Pathol 52: 136-144, 2016.
33. Reich NC: A death-promoting role for ISG54/IFIT2. J Interferon Cytokine Res 33: 199-205, 2013.

34. Yang Y, Zhou Y, Hou J, Bai C, Li Z, Fan J, Ng IOL, Zhou W, Sun H, Dong Q, et al: Hepatic IFIT3 predicts interferon- $\alpha$ therapeutic response in patients of hepatocellular carcinoma. Hepatology 66: 152-166, 2017.

35. Matsuoka M and Green PL: The HBZ gene, a key player in HTLV-1 pathogenesis. Retrovirology 6: 71, 2009.

36. Haneji K, Matsuda T, Tomita M, Kawakami H, Ohshiro K, Uchihara JN, Masuda M, Takasu N, Tanaka Y, Ohta T, et al: Fucoidan extracted from Cladosiphon okamuranus Tokida induces apoptosis of human T-cell leukemia virus type 1-infected T-cell lines and primary adult T-cell leukemia cells. Nutr Cancer 52: 189-201, 2005

37. Vishchuk OS, Sun H, Wang Z, Ermakova SP, Xiao J, Lu T, Xue P, Zvyagintseva TN, Xiong H, Shao C, et al: PDZ-binding kinase/T-LAK cell-originated protein kinase is a target of the fucoidan from brown alga Fucus evanescens in the prevention of EGF-induced neoplastic cell transformation and colon cancer growth. Oncotarget 7: 18763-18773, 2016.

38. Kamihira S, Atogami S, Sohda H, Momita S, Yamada Y and Tomonaga M: Significance of soluble interleukin-2 receptor levels for evaluation of the progression of adult T-cell leukemia. Cancer 73: 2753-2758, 1994.

39. Nishioka C, Takemoto S, Kataoka S, Yamanaka S, Moriki T, Shoda M, Watanabe T and Taguchi H: Serum level of soluble CD30 correlates with the aggressiveness of adult T-cell leukemia/ lymphoma. Cancer Sci 96: 810-815, 2005.

40. Tanaka H, Fujita $\mathrm{N}$ and Tsuruo T: 3 -Phosphoinositide-dependent protein kinase-1-mediated IkappaB kinase beta (IkkB) phosphorylation activates NF-kappaB signaling. J Biol Chem 280: 40965-40973, 2005.

41. Ozes ON, Mayo LD, Gustin JA, Pfeffer SR, Pfeffer LM and Donner DB: NF-kappaB activation by tumour necrosis factor requires the Akt serine-threonine kinase. Nature 401: 82-85, 1999.

42. Dan HC, Cooper MJ, Cogswell PC, Duncan JA, Ting JP-Y and Baldwin AS: Akt-dependent regulation of NF- $\{$ kappa $\}$ B is controlled by mTOR and Raptor in association with IKK. Genes Dev 22: 1490-1500, 2008.

43. Cahill CM and Rogers JT: Interleukin (IL) 1beta induction of IL-6 is mediated by a novel phosphatidylinositol 3-kinase-dependent AKT/IkappaB kinase alpha pathway targeting activator protein-1. J Biol Chem 283: 25900-25912, 2008

44. Brown RT, Ades IZ and Nordan RP: An acute phase response factor/NF-kappa B site downstream of the junB gene that mediates responsiveness to interleukin- 6 in a murine plasmacytoma. J Biol Chem 270: 31129-31135, 1995.

45. Garg AD and Agostinis P: Cell death and immunity in cancer: From danger signals to mimicry of pathogen defense responses. Immunol Rev 280: 126-148, 2017. 